\title{
La nueva fisonomía del derecho administrativo en materia de contratación pública
}

\author{
Antonio Fortes Martín ${ }^{1}$
}

\section{RESUMEN}

El presente trabajo examina las transformaciones ratione personae experimentadas en las últimas décadas por el derecho administrativo en materia de contratación pública. La investigación parte del fenómeno de la europeización del derecho administrativo en su vertiente organizativa o institucional, y su creciente expansión sobre el derecho administrativo de los Estados miembros. Este influjo vertical descendente del derecho de la Unión sobre el derecho español se estudia a partir de la noción europea de Administración pública y su proyección sobre los sujetos, de naturaleza pública y privada, que pasan a quedar sometidos a las normas de la contratación pública. Como resultado, se constata una mutación del esquema orgánico tradicional de la Administración y la conformación de un universo funcional, subjetivamente expandido, representado por el llamado "sector público".

Palabras clave: sector público, Administración pública, contratación pública, derecho administrativo, derecho de la Unión Europea.

1 Doctor en Derecho por la Universidad Carlos III de Madrid, Madrid, España. Profesor titular de Derecho Administrativo de la Universidad Carlos III de Madrid, Getafe-Madrid, España. Correo-e: antonio.fortes@uc3m.es. Enlace ORCID: https://orcid.org/0000-00016770-4932. Fecha de recepción: $1 .^{\circ}$ de julio de 2020. Fecha de modificación: 10 de septiembre de 2020. Fecha de aceptación: 14 de septiembre de 2020. Para citar el artículo: Fortes Martín, AnTONiO, "La nueva fisonomía del derecho administrativo en materia de contratación pública", Revista digital de Derecho Administrativo, Universidad Externado de Colombia, n. ${ }^{\circ}$ 25, 2021, pp. 11-53. DOI: https://doi.org/10.18601/21452946.n25.02. 


\title{
The New Physiognomy of Administrative Law in Public Procurement
}

\author{
ABSTRACT
}

This paper examines the ratione personae transformations experienced in recent decades by Administrative Law in public procurement. It first explores the phenomenon of the Europeanization of Administrative Law in its organizational or institutional domain and its increasing expansion over the Administrative Law of Member States. This downward vertical influence of European Union Law on Spanish Law is then studied from the European notion of public administration and its projection on subjects, of both public and private nature, which fall directly under the scope of public procurement rules. As a result, a mutation of the Administration's traditional organic scheme and the development of a functional, but subjectively expanded universe in the so-called "public sector" are found.

Keywords: Public Sector, Public Administration, Public Procurement, Administrative Law, European Law.

\section{INTRODUCCIÓN}

A modo de "banco de pruebas", el análisis que se propone de la legislación en materia de contratación pública parte de la hipótesis de constatar algunas innovaciones organizativas en el ordenamiento jurídico-administrativo. Como ya lo advirtiera el profesor García de Enterría, "la ciencia jurídica ha sido siempre, es, y no puede dejar de ser, una ciencia de problemas singulares ${ }^{\prime 2}$. Este estudio pretende indagar sobre la delimitación subjetiva del régimen de contratación pública, que en absoluto es neutra, y de la que nos servimos en este trabajo para observar y escrutar lo que aporta una regulación concreta a la teoría general del derecho administrativo.

Cabe advertir que el estudio propuesto no analiza el derecho de la contratación pública en sí considerado, lo que excedería ampliamente del objetivo inicialmente marcado. Más bien se sirve del mismo a modo de "espejo" para encontrar el reflejo de la aplicación subjetiva de la legislación de contratos en el derecho administrativo. La delimitación de la realidad jurídicoadministrativa objeto de este análisis determina, de forma ineludible, una exigencia metodológica que pasamos a especificar a continuación bajo un modelo tipo construido "de arriba hacia abajo". Este modelo nos obliga a analizar en

2 Eduardo García de EnTERría, La lengua de los derechos. La formación del derecho público europeo tras la Revolución francesa, Madrid: Alianza Editorial, 1994, p. 23. 
primer lugar el fenómeno de la europeización del derecho administrativo en su vertiente organizativa o institucional. Una vez superado ese primer estadio ineludible, se está en disposición de ilustrar la acción ordenadora del derecho de la Unión Europea sobre el ordenamiento jurídico interno. En este sentido, la cuestión clave es la noción europea de Administración pública en materia de contratos públicos y su influencia en el derecho administrativo estatal a la hora de concebir una nueva realidad organizativa funcional, el concepto de organismo de derecho público.

Metodológicamente, una vez identificado el anterior concepto, corresponde proyectar hasta sus últimas consecuencias los caracteres del término europeo de organismo de derecho público sobre la legislación estatal en materia de contratación pública. Ese análisis no resulta posible sin la toma en consideración de la función pretoriana ejercida por la jurisprudencia del Tribunal de Justicia de las Comunidades Europeas, que marca el ritmo de la legislación europea y de los Estados miembros. De esta forma, se ofrece un recorrido normativo simultáneo y en paralelo entre el derecho de la Unión Europea y el derecho español. La legislación en materia de contratación pública, que tradicionalmente ha regulado los contratos de las Administraciones públicas, evoluciona hasta los contratos del sector público como categoría amplificada del derecho público. Es en la parte final del trabajo donde se determina la nueva realidad que conforma el llamado sector público con todas sus implicaciones. Un sector público que provoca una afección administrativa no solo de lo público sino también de lo privado, y con claras repercusiones en el derecho administrativo, que pasa a serlo "del sector público". Con todo ello, y en última instancia, se trata de demostrar, en los términos recreados por Muñoz Machado, cómo el derecho administrativo "aporta continuamente innovaciones que provocan mutaciones, no solo en los procedimientos y las técnicas sino también en lo más característico de su sustancia ${ }^{13}$ como lo es en este caso el sujeto que lo caracteriza.

\section{LA EUROPEIZACIÓN DEL DERECHO ADMINISTRATIVO NACIONAL Y LA CONFORMACIÓN DEL DERECHO ADMINISTRATIVO COMO IUS COMMUNE EUROPEO}

El derecho administrativo está sujeto al fuerte influjo del derecho europeo. Esta es una realidad que no ha pasado desapercibida en los últimos años y que se ha explicado como una suerte de europeización a la que se ha referido brillantemente Schmitd-Assmann ${ }^{4}$. Con el fenómeno de la europeización

3 Santiago Muñoz Machado, "Las concepciones del derecho administrativo y la idea de participación en la Administración", Revista de Administración Pública, n. ${ }^{\circ}$ 84, 1977, p. 521

4 Eberhard SChmidt-Assmann, La teoría general del derecho administrativo como sistema. Objeto y fundamentos de la construcción sistemática, Madrid: Marcial Pons - INAP, 2003, pp. 40 y 383. 
del serecho administrativo ${ }^{5}$ se alude a aquel proceso que responde "al influjo, completud y transformación de los ordenamientos nacionales a resultas del impacto que producen los actos y las acciones jurídico-comunitarias"6. Es así como resulta de todo punto imprescindible, permitiéndosenos parafrasear a Thiriez, abordar la que podríamos dar en llamar como la "irrupción del administrativista en el paisaje comunitario" ${ }^{17}$.

En efecto, como en su momento llegara a afirmar Lord Mackenzie Stuart ${ }^{8}$, "One might say that nearly all community law is public law as the original Member States would understand the distinction". En este contexto, y sobre la base establecida por

5 La doctrina iusadministrativista se refiere a esta europeización del derecho administrativo como la novedad más destacada de los últimos quince años en el derecho público. Así, en nuestro país, véase Luciano Parejo Alfonso, Derecho administrativo, Barcelona: Ariel, 2003, pp. 219-221. También JaVIER BARNES, "Sobre el procedimiento administrativo: evolución y perspectivas", en Javier Barnes (ed.), Innovación y reforma en el derecho administrativo, Sevilla: Derecho Global, 2006, p. 321. Y, de manera más reciente, LuIS Arroyo JimÉNEZ, "Derecho administrativo y Constitución española", Revista de Administración Pública, n. o 209, 2019, p. 159. Por lo que se refiere a la doctrina foránea, véanse claramente los trabajos de MARIO P. CHITI, "La aproximación del derecho administrativo nacional a los parámetros europeos: la experiencia italiana", Documentación Administrativa, n. ${ }^{\circ}$ 248-249, 1997, pp. 93-142; SEVERIANO CASSESE, La globalización jurídica, Madrid: Marcial Pons - INAP, 2006, pp. 183-188; MATTHIAS RUFFERT, "De la europeización del derecho administrativo a la Unión administrativa europea", en Francisco Velasco y Jens-Peter Schneider (coords.), La Unión Administrativa Europea, Madrid: Marcial Pons, 2008, pp. 87-107; y THORSTEn SiEGEL, Europeización del derecho público. Marco de condiciones y puntos de interacción entre el derecho europeo y el derecho (administrativo) nacional, Madrid: Marcial Pons, 2016, p. 214.

6 De modo que no hay parcela relevante del derecho administrativo general que no se encuentre actualmente sujeta a la influencia del derecho europeo, como lo ha puesto de manifiesto Eberhard SCHMidT-Assmann, "El derecho administrativo general desde una perspectiva europea", Justicia Administrativa, n. ${ }^{\circ}$ 13, 2001, p. 11.

$7 \quad$ Frédéric Thiriez alude en otro contexto y lugar a "la irrupción del juez penal en el paisaje administrativo" en la cita hecha por Santiago Muñoz Machado al tiempo de abordar el problema de la penalización del derecho administrativo. Véase SANTiago MuÑOz MACHADO, Tratado de derecho administrativo y de derecho público general, t. XII, Actos administrativos y sanciones administrativas, 2. ${ }^{\text {a }}$ ed. Madrid: BOE, 2015, p. 298.

8 Lord Alexander Mackenzie Stuart, The European Communities and the Rule of Law, Londres: Stevens and Sons, 1977, p. 61.

9 Véase con carácter general Armin von Bogdandy y Oriol Mir PuigPelat (coords.), Ius Publicum Europaeum. El derecho administrativo en el espacio jurídico europeo, Valencia: Tirant lo Blanch, 2013. De forma más específica y en el mismo sentido, Ángel Manuel Moreno Molina, La ejecución administrativa del derecho comunitario. Régimen europeo y español, Madrid: Marcial Pons, 1998, p. 30, ha dejado sentado que "el derecho comunitario se mueve constantemente en el magma del derecho administrativo". También, y de forma más reciente, JAVIER BARNES, "Sobre el procedimiento administrativo...", óp. cit., p. 321, advierte cómo "no ha de olvidarse que el derecho europeo y el derecho nacional europeizado es, en esencia, derecho administrativo". Finalmente, SANTIAGo MuÑoz MACHADO, Tratado de derecho administrativo y derecho público general, t. I, 2. ${ }^{\text {a }}$ ed., Madrid: Iustel, 2006, p. 74, se ha referido a que "el derecho común europeo [...] es sustancialmente derecho público [encontrándose] anclado en las tradiciones de los Estados, nutridas de doscientos años de evolución constitucional". 
Schmidt-Assmann ${ }^{10}$ conforme a la cual resulta oportuno reflexionar acerca del derecho administrativo general desde una perspectiva europea, es lógico que nos interroguemos también acerca de lo que el derecho europeo y, más específicamente, el derecho público europeo aporta al debate del derecho administrativo interno en cada uno de los Estados miembros. Y, más en concreto, de lo que el derecho de la Unión Europea proyecta para el reconocimiento e identificación, no solo sustantiva sino también funcional, de la Administración pública y del conjunto de organizaciones y entidades que integran el llamado sector público. Sin embargo, se impone la solución de un interrogante previo, a saber, ¿qué se entiende por derecho público europeo?

Como ya hemos podido constatar, el derecho europeo es sobre todo derecho público. Desde esta perspectiva, el derecho público europeo es, según una primera interpretación, el conjunto de normas y principios que regula la organización y el funcionamiento de las instituciones europeas, así como el conjunto de normas y principios creados por tales instituciones y que las Administraciones nacionales están llamadas a ejecutar ${ }^{11}$. Otra interpretación sostiene que el derecho público europeo es el derecho común a todos los Estados miembros de la Unión Europea ${ }^{12}$. Sea como fuere, estas dos perspectivas no son incompatibles entre sí. Es más, puede llegar a afirmarse que constituyen las dos caras de la misma moneda. Porque el derecho creado por las instituciones europeas es la principal fuente de creación de un derecho común entre todos los Estados miembros ${ }^{13}$, de modo que es así, por antonomasia, el derecho común. A esta tesis conduce una de las características principales del proceso de integración europea conforme a la cual la separación entre lo europeo y lo nacional desaparece, al menos, en aquellos ámbitos en los que se ha producido una cesión de soberanía desde los Estados miembros a favor de la Unión Europea. En esos ámbitos, lo europeo es nacional ${ }^{14}$.

10 Eberhard Schmidt-Assmann, "El derecho administrativo general...", óp. cit., p. 10.

11 Sobre el derecho administrativo europeo, véase la obra indispensable de MARIO P. CHITI y Guido Greco, Trattato di Diritto amministrativo europeo, Milán: Giuffrè Editore, 1997.

12 Véanse Alejandro NieTO, "El derecho comunitario europeo como derecho común vulgar". Revista de Administración Pública, n. ${ }^{\circ}$ 200, 2016, p. 37; y Ricardo Alonso García, "Treinta años de Ius Publicum Commune europeo en España", Revista de Administración Pública, n. ${ }^{\circ} 200$, 2016, p. 342.

13 En los términos recreados por Gil Carlos Rodríguez Iglesias, "Consideraciones sobre la formación de un derecho europeo", Gaceta Jurídica de la Unión Europea y de la Competencia, n. ${ }^{\circ}$ 200, 1999, p. 11.

14 Cabe recordar que meses antes de producirse la incorporación de España a las Comunidades Europeas, LuCiano PaRejo Alfonso, "El ordenamiento español y la integración en las Comunidades Europeas: un problema capital de renovación", Revista Vasca de Administración Pública, n. ${ }^{\circ} 13,1985$, p. 192, ya vaticinaba que el derecho europeo "pasa a situarse como un todo $[\ldots]$ en el derecho interno". 
Por lo tanto, lo europeo es realmente el derecho común a todos los Estados miembros ${ }^{15}$.

Ahora bien, el problema se plantea en los ámbitos materiales en los que esa cesión de soberanía no se ha producido. Aquí es indudable la influencia del derecho europeo que ha conducido y sigue conduciendo en los derechos nacionales tanto al replanteamiento de instituciones jurídicas como a la importación de otras ajenas. A mayor expansión, es la vis atractiva del derecho europeo -ya destacada por Cassese ${ }^{16}$ - la que hace converger hacia sí a derechos divergentes, produciendo un efecto de homogeneización cuando no de convergencia de los sistemas administrativos nacionales ${ }^{17}$. Así pues, el derecho europeo es derecho común a todos los Estados miembros como consecuencia de la cesión o transferencia de soberanía que supone el proceso de integración. $Y$ es derecho que influye sobre los derechos nacionales en los ámbitos no europeizados porque dicha cesión de soberanía no se ha producido. De tal forma que los derechos estatales internos se están transformando para adecuarse a aquel derecho por su mayor "peso" institucional y funcional lo que hace, en última instancia, que prime sobre el derecho nacional ${ }^{18}$.

No obstante lo anterior, se debe mencionar que el derecho europeo aspira a ser expresión y resultado de la confluencia de los derechos nacionales más que a una ruptura de los mismos. Tanto es así que, como ha afirmado Cassese ${ }^{19}$, el derecho europeo presenta caracteres muy próximos a los que son propios de los sistemas administrativos de los países miembros. Extremo que ha confirmado Schwarze al sostener que

la Communauté dispose désormais d'un fonds de règles et de principes de droit administratif qui est totalement comparable à celui des droits administratifs des États membres. Ces règles et principes ont été élaborés principalement en tant que loi prétorienne par la Cour de Luxembourg sur la base des différents ordres juridiques des États membres ${ }^{20}$.

15 La contribución del derecho europeo a la formación del derecho público europeo ha sido también destacada por Eduardo GarCia dE ENTERRIa, La lengua de los derechos..., óp. cit.

16 Severiano CaSSeSE, "Il problema della convergenza dei diritti amministrativi: verso un modello amministrativo europeo?", Rivista trimestrale di diritto e procedura civile, n. ${ }^{\circ} 1,1992, \mathrm{p}$. 31.

17 Una buena prueba de ello lo es, como Mario P. ChiTI, "La aproximación del derecho administrativo...", óp. cit., p. 97 constata, el campo de la contratación pública que "ofrece una oportunidad magnífica para comprobar la naturaleza de la normativa comunitaria y su efecto sobre los derechos internos".

18 Véase Guido GRECO, "Il Diritto comunitario propulsore del Diritto amministrativo europeo", Rivista trimestrale di Diritto Pubblico, n. ${ }^{\circ} 1,1993$.

19 SeVERIANo CASSESE, "Il Diritto amministrativo comunitario e la sua influenza sulle amministrazioni pubbliche nazionali", en Luciano Vandelli, Carlo Bottari y Donato Donati (dirs.), Diritto Amministrativo Comunitario. Col. Quaderni della Spisa, Rímini: Maggioli Editore, 1994, p. 17.

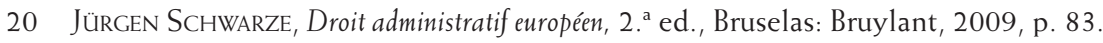


Se produce de este modo una interacción entre el derecho europeo y el derecho nacional que tiene lugar a través de la europeización de parcelas o franjas del derecho nacional, como consecuencia de la indicada cesión o transferencia de soberanía. Esta interacción es, como todas las interacciones, de doble dirección. Ya hemos indicado que el derecho europeo influye decisivamente sobre los derechos nacionales (influencia descendente), pero también la influencia se produce en la dirección contraria (o ascendente) de los derechos nacionales al derecho europeo. Es así como el derecho europeo constituye un vehículo de homogeneización de las diferentes normativas nacionales, a través de un proceso constante de naturaleza recíproca de asunción por parte del derecho europeo de principios e institutos jurídicos ya existentes en algunos Estados miembros, por un lado. Y, por otro, de influencia del derecho público europeo en los ordenamientos de los distintos países de la Unión Europea. Tanto es así, como ha destacado Muñoz Machado ${ }^{21}$, que el derecho europeo está estableciendo condicionamientos ${ }^{22}$ directos y positivos que obligan a los Estados miembros a asumir procedimientos de decisión concretos y específicos, como evidencian las regulaciones europeas, entre otras, en materia de contratación pública. Estas transformaciones están provocando, en palabras del Consejo de Estado francés ${ }^{23}$, la mutación de las instituciones y principios que habían caracterizado siempre al Droit administratif.

De la interacción apuntada entre los derechos nacionales y el derecho público europeo, la vertiente descendente es la que más interesa a los efectos de este trabajo. En el seno de esta interacción subyace la cuestión planteada ut supra acerca de lo que aporta el derecho público europeo al debate respecto de la definición del derecho administrativo interno. Lo anterior, ya que la respuesta a este interrogante, en el que tiene un papel principal la concepción de Administración pública, es una de las principales vías de influencia del derecho europeo respecto de los derechos nacionales, tal y como lo establece Cassese ${ }^{24}$.

En el derecho europeo no existe una noción formal de Administración pública. El Tribunal de Justicia utiliza nociones ad boc en función del efecto útil que quiere alcanzar en cada momento. Así, emplea una noción estricta de Administración pública cuando el efecto útil que se quiere producir es restringir

21 Santiago Muñoz Machado. "Los principios generales del procedimiento administrativo comunitario y la reforma de la legislación básica española", Revista Española de Derecho Administrativo, n. ${ }^{\circ} 75,1992$, p. 343.

22 Más recientemente, pero defendiendo la misma tesis, Santiago Muñoz Machado. Tratado de derecho administrativo..., óp. cit., p. 73.

23 Con cita de Santiago Muñoz MaChado, La Unión Europea y las mutaciones del Estado, Madrid: Alianza Universidad, 1993, p. 47.

24 SeVERIANO CASSESE, "Diritto amministrativo comunitario e diritti amministrativi nazionali", en Mario P. Chiti y Guido Greco, Trattato di Diritto amministrativo europeo, vol. I, Milán: Giuffrè Editore, 1997, p. 10. 
una regla que excepciona o limita el ámbito de una libertad europea ${ }^{25}$. Por contra, maneja una noción amplia cuando el efecto que se quiere producir es el de extender el ámbito de aplicación de una regla europea establecida para facilitar el ejercicio de una libertad también europea ${ }^{26}$. De lo anterior se colige con facilidad que el concepto manejado es variable, en atención a los resultados que, justamente y de manera particularizada, se desean alcanzar. Hasta el punto que se llega a hablar del concepto de Administración pública como una noción cambiante y de "geometría variable"27.

El concepto de derecho administrativo, como es práctica usual en la lógica y en el método científico, debe formularse sobre la base de lo que constituye el núcleo del fenómeno ${ }^{28}$ y no su halo, como por otra parte ya nos advirtiera Morin ${ }^{29}$. Por ello, no extraña comprobar que, como ocurre con la noción europea de Administración pública, el mismo concepto quede a expensas de lo que en cada derecho nacional se considera que es "Estado" o, lo que es lo mismo, el sujeto titular de prerrogativas, poderes o potestades propios de la soberanía. Para Massera es "de sentido común que el derecho comunitario no se ha empeñado en la definición de la noción de Administración pública" ${ }^{\prime 30}$ y ello no solo por la dispersión y mutabilidad de dicho concepto en el espacio europeo, sino también por causa de "factores que son intrínsecamente propios del ordenamiento comunitario y de su posición en las relaciones con los

25 Véanse sentencias del TJCE de 30 de mayo de 1989 (asunto C-33/88), de 27 de noviembre de 1991 (asunto Caso Annegret Bleis contra Ministère de l'Education Nationale) y de 2 de julio de 1996 (asuntos Comisión Europea contra Grecia y Comisión Europea contra Luxemburgo).

26 Es el caso, entre otras, de las sentencias del TJCE de 20 de septiembre de 1988 (asunto C-31/87) y de 12 de diciembre de 2002 (asunto C-470/99)

27 Alberto Massera, "Una nozione comunitaria di pubblica amministrazione", en VV. Aa., El desenvolupament del Dret administratiu europeu, Barcelona: Escola d'Administració Pública de Catalunya, 1993, p. 55.

28 Como bien ha determinado Oriol Mir PuigPelat, "El concepto de derecho administrativo desde una perspectiva lingüística y constitucional", Revista de Administración Pública, n. ${ }^{\circ}$ 162,2003, p. 48, "la historia del derecho administrativo es la historia de la búsqueda de su concepto". Una búsqueda que, como advirtiera Ramón Martín Mateo, Manual de derecho administrativo, Cizur Menor: Thomson Aranzadi, 2005. p. 62, se convierte en una verdadera tautología ya que "si decimos que el derecho administrativo es el derecho de la Administración, debemos definir previamente qué es Administración". En definitiva, y en los términos ya advertidos por Santiago Muñoz MaChado, "Las concepciones del derecho administrativo...", óp. cit., p. 520, "la larga historia de la búsqueda de un criterio único con arreglo al cual definir el derecho administrativo, es a la vez la pequeña historia de sucesivas frustraciones [...]. Todo parece, en fin, conducir a hacer razonable la duda sobre si es viable la definición del derecho administrativo conforme a un criterio único".

29 Véase Édgar Morín, Introducción al pensamiento complejo, Barcelona: Gedisa, 1992.

30 Alberto Massera, "Una nozione comunitaria...", óp. cit., p. 55. 
ordenamientos nacionales ${ }^{1131}$. Entre esos factores destacamos la carencia de separación de poderes en el ordenamiento europeo y la autonomía institucional de los Estados miembros. En concordancia con esto, el derecho europeo reconoce la autonomía institucional y funcional de los derechos nacionales para organizar a las Administraciones nacionales territoriales ${ }^{32}$. Ahora bien, las notas que el derecho europeo maneja-personalidad, poder e interés general- lo son por reflejo de su presencia más que contrastada en el seno de los derechos administrativos nacionales.

Y la consecuencia más destacada y a la hora de constatar lo que aporta el derecho europeo a los derechos nacionales es que el primero se apoya indudablemente en una mordiente más funcional que subjetivista, orgánica o institucional. Es esa vertiente o criterio funcional el que ha desplegado toda la virtualidad del derecho europeo en relación con su impacto e incidencia sobre los derechos nacionales a la hora de conformar una nueva fisonomía del derecho administrativo, sobre todo, en materia de contratación pública.

\section{LA NOCIÓN EUROPEA DE ADMINISTRACIÓN PÚBLICA Y LA DEFINICIÓN DE UNA NUEVA "IDENTIDAD FUNCIONAL" EN MATERIA DE CONTRATACIÓN PÚBLICA}

Schmidt-Assmann ha llegado a advertir que "el derecho comunitario estrictamente vinculado desde un punto de vista competencial no se queda en las formas de actuación unilateral (artículo 189 TCE) sino que reconoce expresamente los contratos jurídico-públicos y privados como medio de la acción de la Comunidad" ${ }^{\prime \prime 3}$.

De hecho, la contratación pública es uno de los campos, dentro de las formas jurídicas de la actuación administrativa, que, sin duda alguna, "han caído en el campo gravitatorio del derecho administrativo comunitario" ${ }^{\prime 34}$. No es casual, por ello, que la normativa europea se haya constituido en el referente obligado, desde la adhesión de España a las Comunidades Europeas, de nuestra normativa de contratos públicos como ninguna otra que integra el corpus del sistema administrativo.

31 Ibíd

32 Así, por ejemplo, a partir del reconocimiento de la libre circulación de trabajadores dentro de la Unión Europea, al amparo del artículo 45.1 de la versión consolidada del Tratado de Funcionamiento de la Unión Europea, el apartado 4 de ese mismo precepto excepciona que "las disposiciones del presente artículo no serán aplicables a los empleos en la Administración pública". Con esto se demuestra que la noción que se tenga y se sostenga de Administración pública va a incidir, directa y derechamente, sobre el ámbito y extensión del ejercicio de la libertad de circulación de personas, concretamente de trabajadores dentro de la Unión Europea

Ibíd., p. 43. 
Las compras de las Administraciones públicas stricto sensu representaban en 1986, justo en el año de ingreso de España a la entonces Comunidad Económica Europea, aproximadamente un $9 \%$ del producto interior bruto (PIB) de la Comunidad Europea. Si a ese escenario se le añaden las operaciones contractuales de las entidades instrumentales de las distintas Administraciones territoriales, el porcentaje se elevaba a un 15\% del PIB de la Unión Europea. Cifra que, más recientemente ${ }^{35}$, representa casi un 20\% del PIB de la hoy Unión Europea. Pese a que las cifras pueden variar sensiblemente en este último lustro, los datos anteriores evidencian que el "mercado público" de la contratación presenta una enorme importancia. Y no es extraño, a la vista de lo anterior, que una de las preocupaciones constantes de los últimos años para la Comisión Europea haya sido abrir como fuere este mercado a la libre competencia. Porque lo que claramente y ante todo persiguen las directivas "de cuarta generación" ${ }^{136}$ no es otra cosa que el funcionamiento transparente del mercado de la contratación pública. De hecho, como el considerando n. ${ }^{\circ} 3$ de la Directiva 2014/23, de 26 de febrero, relativa a la adjudicación de contratos de concesión, y el considerando n. ${ }^{\circ} 2$ de la Directiva 2014/24, de 26 de febrero, sobre contratación pública y por la que se deroga la Directiva 2004/18/CE, reconocen, la contratación pública desempeña un papel clave en la Estrategia Europa 2020, "ya que es uno de los instrumentos basados en el mercado destinados a conseguir un crecimiento inteligente, sostenible e integrador y fomentar al mismo tiempo la utilización más eficiente posible de los fondos públicos".

Es claro también que el legislador español, en el Preámbulo de la vigente Ley 9/2017, de 8 de noviembre, de Contratos del Sector Público, por la que se transponen al ordenamiento jurídico español las directivas del Parlamento Europeo y del Consejo 2014/23/UE y 2014/24/UE, de 26 de febrero de 2014 (en adelante LCSP17), "confiesa" que la LCSP17 no es simplemente el resultado de la transposición de estas dos directivas citadas. Más bien, con esta norma se pretende pergeñar "un sistema de contratación pública más eficiente, transparente e íntegro, mediante el cual se consiga un mejor cumplimiento de los objetivos públicos". De manera que si ese mercado público de contratación queda cerrado un importante ámbito de la actividad económica se situaría al margen de las leyes de la competencia, así como de las libertades europeas relativas a la libre circulación de mercancías, la libre circulación de servicios y el derecho de establecimiento.

Una de las vías, si no la más importante, para hacer realidad esta apertura es mediante la regulación de la contratación pública. En este caso, estas normas

35 Comunicación de la Comisión Europea com (2015) 614 final, de 2 de diciembre titulada "Cerrar el círculo: un plan de acción de la UE para la economía circular".

36 Directiva 2014/23, de 26 de febrero, relativa a la adjudicación de contratos de concesión, y Directiva 2014/24, de 26 de febrero, sobre contratación pública y por la que se deroga la Directiva 2004/18. 
tienen por finalidad garantizar la libre competencia y las demás libertades europeas. El objetivo es eliminar las restricciones que impiden la plena vigencia de estas libertades conformando una suerte de espacio europeo común de contratación pública. Y es en este contexto donde resulta lógico que las directivas europeas relativas a la contratación pública contengan, desde su origen, una noción de Administración pública caracterizada por su amplitud ${ }^{37}$. De esta forma, y al utilizarse un concepto amplio, es mayor el ámbito subjetivo cubierto por las directivas europeas y, por la propia fuerza que imprime la lógica de las cosas, mayor el ámbito de la contratación pública en el que se garantizan el respeto de las libertades europeas ${ }^{38}$.

Las hoy día derogadas directivas 92/50, de 18 de junio, 93/36, de 14 de junio, y 93/37, de 14 de junio, sobre coordinación de los procedimientos de adjudicación de contratos públicos de servicios, suministros y de obras, respectivamente, contenían una definición similar de los sujetos que debían ser considerados como poderes adjudicadores a los efectos de quedar sometidos a las reglas de contratación contenidas en las mismas. Las entidades o poderes adjudicadores eran "el Estado, los entes territoriales, los organismos de derecho público y las asociaciones constituidas por uno o más de dichos entes o de dichos organismos de derecho público ${ }^{139}$. Más específicamente, mientras que las Administraciones públicas en sentido estricto (o territoriales) son simplemente enumeradas, los organismos de derecho público son objeto de definición en atención a determinados criterios autónomos y específicos del derecho europeo ${ }^{40}$. De este modo, los organismos de derecho público venían definidos como "cualquier organismo" en el que concurrieran, acumulativa y simultáneamente, las tres características siguientes que reproducían idénticamente el apartado b del artículo 1 de la Directiva 92/50, de 18 de junio, y de las directivas $93 / 36$ y 93/37, de 14 de junio, a saber:

37 Una caracterización de la Administración pública que, definida así, de acuerdo con criterios generales, puede gozar de relevancia incluso para otros campos distintos al de la contratación pública y con proyección para el conjunto del derecho administrativo en general. Véase Mario P. ChITI, "La aproximación del derecho administrativo nacional...", óp. cit., p. 102

38 Ya que la regulación europea en materia de contratación pública ha de ser uniforme en todos los Estados miembros, no pudiendo depender su aplicación y alcance de las variantes organizativas internas que estos presenten. No obstante, Juan Alfonso Santamaría PasTOR, "Contratos del sector público y derecho de la Unión", Revista de Administración Pública, n. ${ }^{\circ} 200,2016$, p. 89 , ha criticado la conversión del derecho europeo de contratos en una legislación uniforme, como quiera que la Unión Europea no cuenta con competencias explícitas en la materia.

39 Artículo 1, apartado b.

40 Como ha precisado Carmen Chinchilla Marín, "El derecho de la Unión Europea como freno a la huida del derecho administrativo", Revista de Administración Pública, n. ${ }^{\circ}$ 200, 2016 , p. 370 . 
a) "creado para satisfacer específicamente necesidades de interés general que no tengan carácter industrial o mercantil";

b) "dotado de personalidad jurídica";

c) "cuya actividad esté mayoritariamente financiada por el Estado, los entes públicos territoriales u otros organismos de derecho público, cuya gestión se halle sometida a un control por parte de estos últimos, o cuyo órgano de administración, de dirección o de vigilancia esté compuesto por miembros de los cuales más de la mitad sean nombrados por el Estado, los entes públicos territoriales u otros organismos de derecho público".

A resultas de lo anterior, las directivas originarias en materia de contratación administrativa ${ }^{41}$ se servían de la técnica de distinguir, por un lado, los sujetos públicos en sentido estricto: el Estado y los entes territoriales quienes comparten los atributos propios del poder público. Y, por otro lado, las directivas aludían, de una manera que ha sido considerada por Chiti como de "bastante críptica"42, a los organismos de derecho público con la intención de crear así un cuerpo único y coherente de normas sobre contratación pública para todos los Estados miembros a través de la definición funcional de lo que pasa a denominarse "poder adjudicador ${ }^{\prime \prime 3}$. De esta forma, queda claramente atestiguado que el organismo de derecho público se erige en "un concepto de derecho comunitario con una influencia directa en los ordenamientos de los Estados miembros ${ }^{\prime \prime 4}$ que alcanza hasta la actualidad.

$Y$ ante la dificultad de enumerar qué sujetos encajan en esta definición de organismo de derecho público, las primeras directivas en materia de contratación administrativa ${ }^{45}$ pergeñan unos criterios, suficientemente ilustrativos,

Véase también el artículo 1 de la Directiva 71/305, de 26 de julio, sobre coordinación de los procedimientos de adjudicación de los contratos públicos de obras, y el artículo 1 de la Directiva 77/62, de 21 de diciembre de 1976, de coordinación de los procedimientos de adjudicación de contratos públicos de suministro.

42 Mario P. Chiti, "El organismo de derecho público y el concepto comunitario de Administración pública", Justicia Administrativa, n. ${ }^{\circ} 11,2001$, p. 38.

43 Ya el TJCE, en su sentencia de 20 de septiembre de 1988 (asunto C-31/87), había sostenido que, "para dar plenos efectos al principio de libre circulación, el concepto de entidad adjudicadora debe recibir una interpretación funcional" (apartado 11). Este concepto de poder adjudicador pasa a convertirse en uno de los ejes de la aplicación de las leyes estatales de contratación pública al imponerse como consecuencia de la incorporación al derecho español de las directiva europeas de contratación. Una noción no exenta, al mismo tiempo, de crítica, como ha llegado a manifestar el Consejo de Estado en su Dictamen 1116/2015, de 10 de marzo de 2016, al anteproyecto de Ley de contratos del sector público (p. 46). El alto órgano consultivo enfatiza que se trata de una mera copia de la expresión anglosajona para referirse a las entidades contratantes sujetas a la regulación básica contenida en la directiva europea, pero sin correspondencia y tradición en nuestro ordenamiento jurídico interno.

45 Realmente el concepto europeo de "organismo de derecho público", en los términos que ya nos constan, es introducido en el artículo 1, apartado b, de la Directiva 71/305, de 
de cara a su cabal identificación. Unos criterios funcionales para caracterizar a los "organismos de derecho público", como la satisfacción del interés general, y otros criterios formales tales como la personalidad jurídica y el control por parte de una Administración pública. Todo ello sin perjuicio de que en el anexo I de cada una de las primeras directivas en materia de contratación pública figuraban las listas, país por país ${ }^{46}$, de los organismos y de las categorías de organismos de derecho público que reúnen los criterios mencionados.

La noción (europea) de Administración pública que resulta de estas primeras directivas es ya amplia al abarcar tanto a la Administración pública territorial como a la llamada Administración instrumental o institucional. Esquema que se reproducirá miméticamente en nuestro derecho estatal interno cubriendo, así de este modo, y parafraseando a García Pelayo, "toda una gama de formas típicas y atípicas de autonomía administrativa de la economía estatal"47. En este sentido, la normativa interna de contratación pública se ha construido en torno al contrato de la Administración pública pasando de una concepción restringida -solo la Administración del Estado ${ }^{48}$ - a una noción más amplia -como comienza a apuntarse a partir de $1986^{[49]}$ y se consagra de manera definitiva

26 de julio, sobre coordinación de los procedimientos de adjudicación de los contratos públicos de obras en la nueva redacción dada a ese apartado por la modificación operada por la Directiva 89/440, de 18 de julio, que modifica la Directiva 71/305/CEE sobre coordinación de los procedimientos de celebración de los contratos públicos de obras.

En el caso de España esa lista se ha ido "engordando" desde una escueta mención inicial a "Las demás personas jurídicas sometidas a un régimen público de adjudicación de contratos", pasando por la enumeración de los distintos departamentos ministeriales del Gobierno de la Nación, hasta la inclusión de una verdadera tipología de organismos: entidades gestoras y servicios comunes de la seguridad social, organismos autónomos de la administración del Estado, organismos autónomos de las comunidades autónomas, organismos autónomos de las entidades locales, y otras entidades sometidas a la legislación de contratos del Estado español.

47 Véase Manuel García Pelayo, Las transformaciones del Estado contemporáneo, 2. ${ }^{a}$ ed., Madrid: Alianza, 1992, pp. 171-172.

48 En el artículo 1 del Decreto 923/1965, de 8 de abril, por el que se aprueba el texto articulado de la Ley de contratos del Estado se alude de manera expresa a "Los contratos que tengan por objeto directo la ejecución de obras o la gestión de servicios del Estado o la prestación de suministros al mismo". En igual sentido, el artículo 5 de la misma Ley de contratos del Estado de 1965 se refiere a que "El Estado podrá contratar la ejecución de obras, servicios o suministros". En desarrollo de ese texto legal, primero el Decreto 3354/1967, de 28 de diciembre, por el que se aprueba el Reglamento General de Contratación aludía expresamente en su artículo 1 a "Los contratos que celebren los órganos de la Administración del Estado". Y, posteriormente, el Decreto 3410/1975, de 25 de noviembre, delimitaba en su artículo 1 su ámbito de aplicación para "Los contratos que celebre la Administración del Estado".

49 En ese año se aprueba el RD-Legislativo 931/1986, de 2 de mayo, por el que se dio nueva redacción a algunos artículos y se incorporaron otros al texto articulado de la Ley de Contratos del Estado de 1965 con el efecto de conseguir hacer extensiva su aplicación al conjunto de todas las Administraciones publicas y cumplir, de este modo, tanto con las 
en el año $1995^{[50]}$ por mor de las citadas directivas europeas- en su aplicación "a todas las Administraciones públicas"51.

Llegados a este punto, son dos los criterios más relevantes que deben destacarse en materia de contratación pública. Por un lado, la titularidad de poderes públicos. Y, de otro lado, la satisfacción de necesidades de interés general. El primer criterio permite que las Administraciones en sentido estricto (las Administraciones territoriales) queden cubiertas, directa y cabalmente, por la acción de las directivas europeas. El segundo criterio - eminentemente funcional ${ }^{52}-$ es el que sirve fundamentalmente para caracterizar a los organismos de derecho público y poder así insertarlos en la disciplina de los contratos públicos. Esta tesis normativa encontraría su respaldo, poco después, en la jurisprudencia del Tribunal de Justicia de las Comunidades Europeas (en adelante TJCE), a modo de "derecho pretoriano" y anticipando la regulación finalmente contenida en las directivas de contratación pública ${ }^{53}$.

obligaciones contraídas por España por su pertenencia a la Comunidad Europea, como con el mandato constitucional del artículo 149.1.18 CE. Este mismo criterio fue seguido, meses más tarde, por el RD 2528/1986, de 28 de noviembre, por el que se modifica el Reglamento General de Contratación del Estado, aprobado por Decreto 3410/1975, de 25 de noviembre.

50 Donde el artículo 1 de la Ley 13/95, de 18 de mayo, de contratos de las Administraciones públicas ya distingue, por un lado, a las Administraciones territoriales (apartado 2) de los "Organismos autónomos en todo caso y las restantes entidades de derecho público con personalidad jurídica propia vinculadas o dependientes de cualquiera de las Administraciones públicas" (apartado 3). Posteriormente, y en los mismos términos, véase el artículo 1 del RD-Legislativo 2/2000, de 16 de junio, por el que se aprueba el Texto Refundido de la Ley de contratos de las Administraciones Públicas.

51 La Exposición de Motivos de la Ley 13/95, de 18 de mayo, de contratos de las Administraciones públicas es muy clara en este sentido al afirmar en su apartado 1.2 que la pertenencia de España a la entonces Comunidad Europea (hoy Unión Europea) exige la adaptación de nuestra legislación interna al ordenamiento jurídico europeo, recogido, en materia de contratación administrativa, en diversas directivas sobre contratos de obras, suministros y servicios, y que resultan "aplicables, precisamente por su carácter de derecho comunitario, a todas las Administraciones públicas".

52 No está de más recordar que, de conformidad con las tesis funcionalistas del derecho administrativo y como ha afirmado FrançoIs BuRdeau, Histoire du Droit administratif, París: UPF, 1995, p. 343, la razón de ser del derecho administrativo pasa a ser la satisfacción de las necesidades de interés general y no el poder.

53 Véase con carácter general Michele Cozzıo. "La función de la jurisprudencia en el proceso de europeización de las reglas de contratación pública", en José María Gimeno Feliu (dir.), Observatorio de contratos públicos 2012, Cizur Menor: Thomson Civitas, 2013, pp. 89-116. Cfr. José María Gimeno Feliu, "La 'codificación' de la contratación pública mediante el derecho pretoriano derivado de la jurisprudencia del TJuE", Revista Española de Derecho Administrativo, n. ${ }^{\circ} 172,2015$, pp. 81-122. También Carmen ChinChilla Marín, "La jurisprudencia del tJuE sobre contratos públicos (I): ámbito subjetivo y objetivo de aplicación de las directivas", en Miguel Sánchez Morón (dir.), El derecho de los contratos públicos en la UE y sus Estados miembros, Valladolid: Lex Nova, 2011, pp. 33-79. Por otra parte, esta jurisprudencia europea, en los términos destacados por MARIO P. CHITI, "El organismo de derecho público...", óp. 
Así acontece con la sentencia del TJCE de 15 de enero de $1998^{[54]}$. En esta sentencia, el TJCE se enfrenta a la necesidad de aclarar la noción europea de organismo de derecho público como consecuencia de una cuestión prejudicial planteada por el Bundesvergabeamt austríaco en el seno de un litigio surgido como consecuencia de la licitación de un proyecto relativo a las instalaciones técnicas de una imprenta promovido por la Österreichische Staatsdruckerei (ÖS), y si el mismo debía o no ajustarse a la licitación pública pese a encontrarnos ante una entidad pública. A la vista de la naturaleza de la ÖS, el TJCE falla afirmando su carácter de organismo público a los efectos de la Directiva 93/37, sin que a tal conclusión pueda hacer sombra el hecho de que la ÖS realiza, además de ciertas actividades de interés general, otras de carácter mercantil o dirigidas al mercado, como la edición y distribución de libros y periódicos ${ }^{55}$. Para alcanzar esa respuesta, el TJCE se plantea si la ÖS es un organismo público, extremo resuelto positivamente por cuanto cumple con todos los requisitos expuestos en la Directiva 93/37. A tal fin, hay que recordar que la directiva en cuestión definía estos organismos como "cualquier organismo creado para satisfacer específicamente necesidades de interés general que no tengan carácter industrial o mercantil, dotado de personalidad jurídica, y cuya actividad depende estrechamente del Estado, de los entes territoriales o de otros organismos de derecho público". Unos criterios que, a juicio del TJCE, se cumplen perfectamente respecto de la situación de ÖS, concluyendo que"la ÖS debe ser calificada como organismo de derecho público en el sentido del párrafo segundo de la letra b) del artículo 1 de la Directiva 93/37 y, por consiguiente, debe ser considerada un órgano de contratación en el sentido del párrafo primero de dicha disposición ${ }^{\prime \prime 5}$.

Esta recreación evidencia, a todas luces, que la caracterización jurídica de los organismos públicos pasa porque hayan sido creados para satisfacer una necesidad de interés general que no tenga carácter industrial o mercantil. Ahora bien, este criterio encierra, al mismo tiempo, considerables problemas

cit., p. 38, presenta una importancia destacada. Porque a través sobre todo de recursos prejudiciales, el Tribunal de Justicia ha ido estableciendo una interpretación vinculante del derecho europeo, más en concreto, acerca de la cualificación y tipificación de figuras jurídicas subjetivas perfectamente definidas en los ordenamientos nacionales y de dudosa definición europea con respecto a los objetivos de la aplicación de la normativa sobre los contratos públicos, como es ahora, por lo que más nos interesa, el caso del organismo de derecho público.

54 TJCE de 15 de enero de 1998, asunto C-44/96.

55 Con ello, Mario P. Chitı, "El organismo de derecho público...", óp. cit., p. 45, alude al gran valor que presenta este pronunciamiento por cuanto la calificación de un sujeto como organismo de derecho público -válida en la totalidad de las acciones emprendidas por el mismo- lo es incluso por referencia solo a una parte de sus actividades $y$, por tanto, aun cuando ese mismo sujeto opere en el mercado.

56 Apartado 29 de la sentencia del TJCE de 15 de enero de 1998, asunto C-44/96. 
prácticos, tal y como se le evidenciaron al TJCE en la sentencia de 10 de noviembre de $1998^{[57]}$.

En este otro pronunciamiento, el TJCE resuelve la cuestión prejudicial planteada por el Gerechtshof te Arnhem de los Países Bajos sobre la interpretación de la letra b del artículo 1 de la Directiva 92/50 del Consejo, de 18 de junio de 1992, sobre coordinación de los procedimientos de adjudicación de los contratos públicos de servicios. La cuestión prejudicial se planteó en el seno de un litigio entre unos municipios holandeses (Gemeente Arnhem y Gemeente Rheden) y una empresa privada -BFI Holding BV-que, entre otras actividades, se dedicaba a la recogida y tratamiento de residuos domésticos e industriales. El litigio surgió, a su vez, como consecuencia de la creación, por los municipios citados, de una empresa -la Sociedad Anónima ARA- para que prestase los servicios de recogida de los residuos domésticos e industriales, así como los de limpieza viaria, en sus respectivas localidades. Y todo de cara a despejar la eventual aplicación o no de la Directiva 92/50 a la adjudicación del contrato concedido a ARA.

El Tribunal holandés en la instancia -y que planteó la cuestión prejudicial- no ponía en duda que la empresa ARA cumplía con dos de los tres requisitos enumerados en el artículo 1 apartado b de la Directiva 92/50 ${ }^{[58]}$. Ahora bien, el problema se centraba en la interpretación del primero de los tres requisitos relativo a "la satisfacción de una necesidad de interés general que no tenga carácter industrial o mercantil". Una interpretación que el Tribunal realiza afirmando que "el párrafo segundo de la letra b) del artículo 1 de la Directiva 92/50 debe interpretarse en el sentido de que el legislador distingue entre necesidades de interés general que no tienen carácter industrial o mercantil y necesidades de interés general que tienen carácter industrial o mercantil" ${ }^{\prime \prime}$.

De esto resulta que la actividad de satisfacción de las necesidades de interés general es la categoría general que admite, a su vez, dos tipos: el primero, las actividades que formando parte de la categoría indicada no tienen carácter industrial o mercantil. Y, el segundo, el integrado por las que sí lo tienen, por lo que resulta perfectamente posible que se satisfaga un interés general a través de actividades de carácter industrial o mercantil ${ }^{60}$.

Más aún, el TJCE afirma en su pronunciamiento, siguiendo la doctrina previa de la sentencia de 15 de enero de $1998^{[61]}$, que la "condición de organismo de

Sentencia del TJCE de 10 de noviembre de 1998, asunto C-360/96.

Concretamente, el contar con personalidad jurídica y estar bajo el control de los municipios que la constituyeron.

Apartado 36 de la sentencia del TJCE de 10 de noviembre de 1998, asunto C-360/96.

Posibilidad, esta última apuntada en el texto principal, que permite sostener que las necesidades de interés general pueden llegar a ser satisfechas tanto por organismos públicos como por empresas.

1 Sentencia del TJCE de 15 de enero de 1998, asunto C-44/1996. 
derecho público no depende de la importancia relativa, en la actividad del organismo de que se trata, de la satisfacción de necesidades de interés general que no tengan carácter industrial o mercanti1 ${ }^{62}$. También es indiferente que una persona jurídica distinta, que forme parte del mismo grupo que dicho organismo, ejerza actividades mercantiles" ${ }^{163}$.

Por último, afirma el TJCE que "el párrafo segundo de la letra b) del artículo 1 de la Directiva 92/50 debe interpretarse en el sentido de que la existencia o inexistencia de necesidades de interés general que no tengan carácter industrial o mercantil ha de apreciarse objetivamente, siendo indiferente para ello la forma jurídica ${ }^{64}$ de las disposiciones en las que se especifiquen dichas necesidades" ${ }^{\prime \prime 5}$.

A la vista de lo anterior, la doctrina jurisprudencial del TJCE filtra la forma de desentrañar cuál es el concepto europeo de Administración pública ${ }^{66}$. De este modo, el derecho europeo, a través de la normativa en materia de contratación pública, delimita, nítida y claramente, la distinción entre lo que podemos denominar Administración pública stricto sensu y la Administración institucional. Mientras la primera viene constituida por el Estado y las Administraciones territoriales que lo integran - en tanto que sujetos que tienen atribuidas las cualidades propias del poder público a los efectos de la satisfacción de necesidades de interés general-, la segunda viene referida a los organismos de derecho público. Unos organismos que tienen personalidad jurídica y están bajo el control de alguna Administración pública territorial. Empero, lo que

62 Resulta, por tanto, irrelevante que, además de satisfacer necesidades de interés general, la entidad en cuestión realice otro tipo de actividades que sean de carácter mercantil o industrial, ya que lo importante es que se cumplan funciones de interés general, aunque ello lo sea parcialmente. Véase Martín María RazQuín Lizárraga, "La jurisprudencia del Tribunal de Justicia de las Comunidades Europeas sobre contratación pública", Justicia Administrativa, n. ${ }^{\circ}$ 6, 2000, p. 19.

63 Apartado 58 de la sentencia del TJCE de 15 de enero de 1998, asunto C-44/96. Véase en el mismo sentido, y más recientemente, la sentencia del TJuE de 5 de octubre de 2017 (asunto C-567/15).

64 Posteriormente, la sentencia del TJCE de 1. ${ }^{\circ}$ de febrero de 2001 (asunto C-237/99), reiteró esta jurisprudencia respecto a la indiferencia de la forma jurídica para la apreciación de la concurrencia del primer requisito.

65 Apartado 63 de la sentencia del TJCE de 15 de enero de 1998, asunto C-44/1996. También muy claramente en lo que se refiere a la comprobación objetiva de la satisfacción de tales necesidades, véase sentencia del TJCE de 12 de diciembre de 2002 (asunto C-470/99).

66 Así, desde las sentencias del TJCE de 12 de febrero de 1974 (asunto 152/73) y de 17 de diciembre de 1980 (asunto 149/79), el TJCE viene precisando que el concepto de Administración pública debe interpretarse y aplicarse uniformemente dentro de la Unión Europea, sin dejarse a la discrecionalidad de los Estados miembros. Por esta razón, y gracias a la importante labor desplegada por el TJCE, en los términos destacados por ÁNGEL MANUEL Moreno Molina, La ejecución administrativa..., óp. cit., p. 39, hoy día contamos con una noción "europea" precisa de Administración pública en el campo de los contratos públicos. 
particularmente los singulariza es que satisfacen una necesidad de interés general que no tiene carácter industrial o mercantil.

En este sentido, la noción europea de Administración pública, sobre la base de las primeras directivas en materia de contratación pública, contribuye decisivamente a la delimitación estatal interna del concepto de Administración pública, máxime cuando se pone de relieve la distinción entre Administración en sentido estricto y los organismos que integran la llamada Administración institucional. Un concepto de organismo de derecho público

que forma parte esencial de la problemática comunitaria sobre la Administración pública, y contribuye a definir el ámbito subjetivo de aplicación del derecho comunitario en los Estados miembros, desde una perspectiva fuertemente sustancialística y funciona ${ }^{67}$ que, en sectores relevantes como los contratos de las Administraciones públicas, se diferencia significativamente de los conceptos nacionales de Administración pública ${ }^{68}$.

\section{FINES DE LA ADMINISTRACIÓN E INTERÉS GENERAL EN LA EXTENSIÓN DEL ALCANCE DE LA NOCIÓN DE ADMINISTRACIÓN PÚBLICA}

Como por todos resulta sabido, la Ley 29/1998, de 13 de julio, reguladora de la jurisdicción contencioso-administrativa establece que este orden jurisdiccional conocerá de las pretensiones que se deduzcan en relación con la actuación de las Administraciones públicas sujeta al derecho administrativo, así como también de las pretensiones deducidas en relación con los actos y actuaciones de otros sujetos definidos en el apartado 3 de su artículo 1 . Esta realidad fue en su momento caracterizada por nuestra principal doctrina iusadministrativista como la "fuerza expansiva del contencioso". Una expansión que más bien no supone un cuestionamiento del criterio identificador de la Administración ni del derecho administrativo, ya que

la justificación de este control, que evidencia la fuerza expansiva de la jurisdicción contenciosa $[\ldots]$ debe buscarse no tanto en la asimilación de estos órganos públicos a la Administración cuanto en el derecho fundamental a la tutela judicial efectiva que obliga a no dejar sin protección los derechos e intereses legítimos que puedan resultar afectados por la actuación de los poderes públicos cuando

67 Y que se aleja, por ende, de la perspectiva más subjetivista que parecía primar, por contra, en el derecho originario de la Unión Europea, como resultaba de los artículos 101 y 103 del Tratado de la Comunidad Europea (actuales artículos 123 y 125, respectivamente, de la versión consolidada del Tratado de Funcionamiento de la Unión Europea). Mario P. Chitı, "El organismo de derecho público...", óp. cit., p. 34. 
desarrollen funciones materialmente administrativas aún cuando los órganos actuantes no pertenezcan a la Administración pública ${ }^{69}$.

Nos servimos de esta remisión a la ley española reguladora de la jurisdicción contencioso-administrativa para extraer ahora un dato relevante y que no es otro que el siguiente: ni la sujeción al derecho administrativo ni el control contencioso-administrativo son criterios suficientes para definir cuándo nos encontramos ante una Administración pública. El criterio subjetivo aparece de este modo matizado a través de los fines de la Administración. Empero, que el legislador utilice el criterio de los fines -como el de las potestades- para caracterizar a la Administración pública no significa que este criterio sustituya al criterio de la personalidad. Porque no puede perderse de vista que el legislador utiliza varios criterios y la interpretación conjunta de los mismos modula, ciertamente, el criterio de la personificación jurídica de la Administración, si bien en ningún caso lo hace desaparecer ${ }^{70}$.

La referencia a los fines de la Administración está expresamente incluida en nuestra legislación administrativa ${ }^{71}$ "de cabecera". Esta llamada a los intereses generales tiene una indudable importancia en orden a la caracterización jurídica de las Administraciones públicas. No solo porque a estos mismos intereses generales alude, como no podía ser de otro modo, la Constitución española, sino también por lo referido a una suerte de principio unificador de la acción de la Administración, al servicio de los fines públicos, frente a la diversidad de medios de la misma.

Ese mismo interés general ha sido también utilizado por la legislación administrativa de contratos para delimitar su radio de acción ${ }^{72}$. El artículo 1 de la Ley 13/95, de 18 de mayo, de Contratos de las Administraciones Públicas (en

69 Jesús Leguina Villa, "El ámbito de la jurisdicción", en Jesús Leguina Villa y Miguel Sánchez Morón (dirs), Comentarios a la Ley de la Jurisdicción contencioso-administrativa, 2. a ed., Valladolid: Lex Nova, 2001, p. 39.

70 Porque, como llegara a reconocer Eduardo García de EnTerría, "El concepto de personalidad jurídica en el derecho público", Revista de Administración Pública, n. ${ }^{\circ} 129,1992$, p. 201, el reconocimiento de personalidad constituye "una calificación puramente técnica, un dato que hace posible su funcionamiento como lo que la Administración sobre todo es, una organización".

71 En este sentido, la derogada Ley 30/92, de 26 de noviembre, de Régimen Jurídico de las Administraciones Públicas y del Procedimiento Administrativo Común (en adelante LRJPAC) ya disponía en su artículo 3.1 -transcribiendo el artículo 103.1 CE- que "Las Administraciones públicas sirven con objetividad los intereses generales". Y, en la actualidad, el artículo 3.1 de la vigente Ley 40/2015, de 1. ${ }^{\circ}$ de octubre, de Régimen Jurídico del Sector Público (en adelante LRJSP) recoge idéntica prescripción.

72 Como reconoce el Consejo de Estado en su Dictamen 214/92, de 21 de mayo, emitido sobre el anteproyecto de la que luego sería Ley de Contratos de las Administraciones Públicas de 1995, el "interés general constituye la última ratio de toda esta ordenación normativa". 
adelante LCAP) y del Texto Refundido de la Ley de Contratos de las Administraciones Públicas (en adelante TRLCAP) -aprobado por Real Decreto Legislativo 2/2000, de 16 de junio- referenciaban su ámbito de aplicación distinguiendo entre Administraciones públicas y otras entidades que no lo son, pero que venían a ser consideradas como tales a los efectos de quedar sujetas a lo dispuesto en sendos textos legales ${ }^{73}$. Además, ya hemos tenido ocasión de comprobar en el epígrafe anterior cómo por la acción de las primeras directivas europeas en materia de contratación pública y de la jurisprudencia del TJCE tiene lugar un "estiramiento" en la definición del concepto de Administración pública a partir de la distinción entre Administración pública en sentido estricto y organismo de derecho público.

Mientras en la legislación administrativa general (por todas la derogada LRJPAC y la actualmente vigente LRJSP) el criterio de las potestades administrativas sirve para matizar o modular a su vez el de la personalidad jurídica de derecho público, en la primigenia legislación de contratos de las Administraciones públicas el criterio utilizado es el del interés general. Junto a este criterio también se encuentra el del control de la Administración respecto de la entidad de derecho público que queda sujeta a la legislación de contratos. Sin embargo, es el criterio de la satisfacción de las necesidades de interés general el que ha ocupado un lugar destacado. Ahora bien, no debe perderse de vista que todos estos criterios solo operan respecto de las entidades que no son Administraciones públicas en sentido estricto (o territoriales), sino que lo son por asimilación a los efectos de quedar sujetas a la legislación de contratos públicos. A mayor abundamiento, estos otros entes son identificados, a los efectos indicados, a partir de una serie de criterios que son parcialmente

73 Tanto la LCAP de 1995 como el TRLCAP de 2000 introdujeron elementos de complejidad asistemática a resultas del intento de conciliación de los criterios subjetivos propios de nuestra tradición jurídica con otros funcionales o materiales exigidos desde el derecho europeo. El resultado de esta mixtificación consistió en un triple círculo de aplicación a las normas de contratación pública. En este sentido, podían diferenciarse estos tres niveles de aplicación de la legislación de contratación administrativa: a) a todas las Administraciones territoriales (las que se consideran Administraciones públicas conforme al artículo $1.2)_{i}$ b) a todos los organismos autónomos y entidades de derecho público que actúan en régimen de derecho público; y c) a las entidades de derecho público que actúan en régimen de derecho privado y que han sido creadas para dar satisfacción a una necesidad de interés general o están controladas por una Administración territorial (las que cumplieran con los requisitos del artículo 1.3 que son los reconocidos en el ámbito europeo como los propios del concepto europeo de organismo de derecho público). Finalmente, las entidades de derecho público que actúan en régimen de derecho privado y no cumplen con los requisitos del artículo 1.3 no escapaban a todas las reglas de contratación pública. A estas les resultaban aplicables ciertas reglas dispuestas en el artículo 2 (concretamente las reglas relativas a la capacidad de las empresas, publicidad, procedimientos de licitación y formas de adjudicación) si bien para ciertos tipos de contratos enumerados en el mismo artículo 2 . 
coincidentes con los manejados por la legislación administrativa general. Nos referimos a los criterios de la personalidad y al de la naturaleza de derecho público, aunque no se menciona el criterio de la potestad. En cambio, sí ocupa un lugar relevante el criterio de la satisfacción de necesidades de interés general, debidamente interpretado por la jurisprudencia del TJCE, por lo que no puede afirmarse que exista una contradicción entre potestad y satisfacción de las necesidades de interés general. Y, a nuestro juicio, no constatamos contradicción alguna como quiera que es evidente que estas necesidades se satisfacen por varios medios, uno de los cuales es, indudablemente, el ejercicio de las potestades administrativas. Por otra parte, no puede perderse de vista que las Administraciones públicas tienen como misión el servicio objetivo a los intereses generales, conforme consagra la Constitución española, prescripción que vale con mayor intensidad, aún si cabe, respecto de los organismos que, no siendo Administraciones en sentido estricto, dependen o están vinculados a alguna de ellas.

De lo anterior, se colige que en un primer momento se haya querido utilizar otro criterio más amplio a los efectos de extender el ámbito de sujeción a la legislación de contratos administrativos. Porque el objetivo primordial no es otro que incluir el mayor número posible de entidades ${ }^{74}$. Esta pretensión se ve confirmada a la vista de lo dispuesto en el artículo 2 TRLCAP de 2000. Tras establecer el criterio indicado, en el artículo 2 se intenta extender, al menos de forma parcial, el ámbito de aplicación del TRLCAP de 2000 a las entidades que hubiesen escapado de dicho ámbito por no quedar incluidas como consecuencia de la aplicación de los criterios del artículo 1 TRLCAP de 2000. Esta pretensión obedece a lo que podemos dar en llamar como la "presión" europea. Una presión a la que se ha referido en su momento Parejo Alfonso cuando ha afirmado que

la asunción por el derecho comunitario de un concepto sustantivo o material de empresa [implica] que las actividades de contenido económico desarrolladas o controladas por los poderes públicos nacionales queden sometidos al régimen de la libre competencia, cualquiera que sea su forma jurídica, es decir, aun cuando se realicen por organizaciones administrativas directas, con el resultado de una neta

74 Ya en relación con la LCAP de 1995, Eva DesDEnTADo DaROCA, La crisis de identidad del derecho administrativo: privatización, buida de la regulación pública y Administraciones independientes, Valencia: Tirant lo Blanch, 1999, p. 103, destacaba el notable avance que supuso esta ley "en la recuperación de las garantías del derecho público en el actuar de las organizaciones administrativas". Ahora bien, todavía no quedaban resueltos por completo los problemas de las entidades de derecho público que actuaban en régimen de derecho privado -y que quedaban por ende fuera de su ámbito de aplicación- ni tampoco el de las sociedades mercantiles de su Disposición Adicional 6, a quienes se aplicaban únicamente principios de publicidad y concurrencia pero no los procedimientos de licitación ni adjudicación de la Ley 
diferenciación entre actividades de autoridad y actividades económicas estatales, ya que lo decisivo es la calificación material del contenido -industrial o comercialde tales actividades y no su mera consideración como servicio público ${ }^{75}$.

La presión "administrativa" europea es presión, al fin y al cabo, en favor de la libre competencia como han venido a confirmar tanto la Ley 30/2007, de 30 de octubre, de contratos del sector público (en adelante LCSP07) como, una década más tarde, la vigente Ley 9/2017, de 8 de noviembre, de contratos del sector público (LCSP 17). Esa libre competencia se garantiza, paradójicamente, por el derecho administrativo sometiendo toda la actividad contractual de las Administraciones públicas y sus entidades secundarias a la legislación de contratación pública. En este contexto, la referencia a las potestades administrativas operaría como un criterio reductor contrario al objetivo buscado.

Esta tendencia que perfectamente se colige del TRLCAP de 2000 experimenta una nueva "vuelta de tuerca" ante el "hipernormativismo" europeo ${ }^{76}$ que viene $^{\text {" }}$ arrastrando el régimen de contratos públicos. Una reacción normativa con la consiguiente ampliación de los confines de la noción de Administración pública remediando así también con ello la "huida"77 propiciada por los Estados miembros para que ciertos entes u organismos - por no hallarse formalmente integrados en la Administración pública y someter su actividad al régimen del derecho privado- pudieran mantenerse al margen de la aplicación de la normativa europea sobre contratación pública ${ }^{78}$. Nos referimos al efecto provocado, en un segundo estadio o escalón normativo europeo, por la aprobación de la Directiva 2004/18, de 31 de marzo, sobre coordinación de los procedimientos de adjudicación de los contratos públicos de obras, de suministros y de servicios, y que pasó a sustituir a las anteriores directivas 92/50, 93/36 y 93/37.

76 Mario P. Chiti, "El organismo de derecho público...", óp. cit., p. 38.

77 Huida cuando no fuga del derecho administrativo en los casos en que un ente público desarrolla su actividad, o parte de ella, bajo los dictados del derecho privado. Fenómeno que desembocó en lo que Fernando Garrido Falla, "Origen y evolución de las entidades instrumentales de las Administraciones públicas", en Alfonso Pérez Moreno (coord.), Administración instrumental. Libro bomenaje a Manuel Francisco Clavero Arévalo, vol. I, Madrid: Civitas, 1994, p. 41, denominó muy gráficamente como la "apostasía del derecho administrativo".

78 Véase claramente Sebastián Martín-Retortillo, "Reflexiones sobre la huida del derecho administrativo", Revista de Administración Pública, n. ${ }^{\circ}$ 140, 1996, p. 44. Cfr. también AlfonSo PÉrez Moreno, "La contratación de los entes instrumentales: sociedades mercantiles y demás entidades del sector público", en VV. AA., Comentario a la Ley de contratos de las Administraciones públicas, Madrid: Civitas, 1996, p. 860, quien destaca la funcionalidad del derecho europeo en la materia "como corrector de la fuga del derecho administrativo en la contratación pública". Más recientemente y en los mismos términos, CARMEN CHINCHILLA MARín, "El derecho de la Unión Europea como freno...", óp. cit., p. 368, apunta a la operatividad del derecho de la Unión Europea en materia de contratación pública como verdadero freno a la huida del derecho público. 
De hecho, los efectos de la nueva afección provocada por el régimen normativo europeo en el sistema de contratos de la Administración se han extendido más allá de la normativa de contratación pública stricto sensu alcanzando, incluso, a la esencia de la legislación administrativa general más de diez años después y hasta el momento presente.

\section{LA EMERGENCIA DE UNA NUEVA REALIDAD ORGANIZATIVA: EL "SECTOR PÚBLICO" Y SU CARACTERIZACIÓN SUSTANTIVA O MATERIAL COMO ÁMBITO SUBJETIVO REFERENCIAL DE LA NORMATIVA DE CONTRATACIÓN PÚBLICA}

La Directiva 2004/18, de 31 de marzo, provocó una nueva modulación del criterio de la personalidad jurídica de la Administración como consecuencia de la introducción de criterios materiales aplicados a la contratación. Una contratación que, en el plano estatal interno, pasa a identificarse como "del sector público"77, aspecto este que para nada resulta azaroso o casual, como acto seguido tendremos ocasión de comprobar.

La Exposición de Motivos de la LCSP07 ya apuntaba que

la ley de contratos del sector público ha adoptado un enfoque que, separándose de sus antecedentes, aborda la regulación de la actividad contractual pública desde una definición amplia de su ámbito de aplicación y buscando una identificación funcional precisa del área normativa vinculada a regulaciones europeas, teniendo en cuenta que se trata de una ley que ha de operar en un contexto jurídico fuertemente mediatizado por normas supranacionales y en relación con una variada tipología de sujetos.

Se demuestra con ello que del contrato administrativo y del contrato de la Administración pública pasamos a una nueva perspectiva propia del contrato que celebre cualquier entidad del sector público flexibilizando, justamente, la regulación para algunos entes del sector público -que no son Administraciones públicas- creados para satisfacer necesidades de interés general no industriales ni mercantiles.

La necesidad "asfixiante", por la exigencia europea, de ampliar y extender a toda costa el ámbito subjetivo de aplicación de la normativa de contratos -sobre la base de los logros alcanzados por la normativa anterior- nos sitúa ahora ante un nuevo escenario, no solo de alcance puramente formal, sino plenamente sustantivo o material de lo que sea el "sector público". Para ello nos servimos

79 No solo el título tanto de la LCSP07 como de la LCSP17 pasa a ser de contratos del sector público, sino que sus respectivos artículos 1 disponen expresamente que la Ley tiene por objeto regular "la contratación del sector público". 
de una identificación o una valencia funcional ${ }^{80}$, en terminología empleada por Chiti ${ }^{81}$, de modo que quede así asegurado el efecto útil del derecho europeo en materia de contratos garantizando su más amplia aplicación ${ }^{82}$.

Si se quiere ver de este modo, la LCSP07 propuso en su momento un salto organizativo a otra dimensión, más allá de lo estricta y nominalmente administrativo. Porque "lo administrativo" empieza a transitar por la pasarela funcional del "sector público" hasta el punto de llegar a ser absorbido por este último. De forma que el resultado final, que alcanza hasta nuestros días en el vigente texto de la LCSP17, es que el ámbito subjetivo tradicional de aplicación de los contratos de las Administraciones públicas se dirige, con nuevos bríos, a horizontes más amplios, concretamente a "todos los sujetos del sector público" ${ }^{183}$. Un sector público que ya venía identificando la Ley 47/2003, de 26 de noviembre, General Presupuestaria ${ }^{84}$ en su artículo 2.1, si bien para el sector público estatal y que, por traslación, pasa a orbitar también a la legislación de contratos y, con ella y a través de ella, a la legislación administrativa general. El efecto último es que la legislación de contratos pasa a "administrativizar", desde el estricto punto de vista organizativo, a la legislación administrativa general. Así puede constatarse, cabalmente, tanto en la Ley $39 / 2015$, de $1 .{ }^{\circ}$ de octubre, del procedimiento administrativo común, como en la Ley 40/2015, de $1 .{ }^{\circ}$ de octubre (que lo es del régimen jurídico del sector público). Ambas disposiciones se

80 Donde el elemento determinante es el representado por el perfil funcional del ente u organismo, sin que en ningún momento este sea determinado por la forma organizativa de ese mismo sujeto.

81 Mario P. Chiti, "El organismo de derecho público...", óp. cit., p. 34.

82 Como Mario P. Chitı, "El organismo de derecho público...", óp. cit., pp. 39 y 42, explicita, la Unión Europea adopta su propia posición en los casos en los que la referencia al derecho nacional puede amenazar la aplicación del derecho europeo, como claramente acontece con el concepto de organismo de derecho público en las directivas de contratación pública, o con la interpretación fuertemente restrictiva de la limitación al principio de libre circulación de los trabajadores en lo que se refiere a los puestos en la Administración pública. De este modo, "el concepto comunitario de Administración pública es una de las claves que consienten a las instituciones comunitarias una fuerte influencia sobre las Administraciones de los Estados miembros garantizando, por un lado, la plena aplicación del derecho comunitario según el principio del efecto útil, y, por otro lado, una forma de colaboración efectiva y vigilada con las administraciones públicas nacionales".

83 El Consejo de Estado, en su Dictamen 514/2006, de 25 de mayo, al anteproyecto de la que acabaría siendo la LCSP07, criticó el error de concepción o más bien de construcción que la estructura de la ley tenía. Porque pese a presentarse como una norma de la actividad contractual del entero sector público, empero, el grueso de la regulación a lo largo del articulado de la norma seguía girando sobre normas pensadas únicamente para las Administraciones públicas.

84 De conformidad con lo dispuesto en el artículo 3 de la Ley 47/2003, de 26 de noviembre, General Presupuestaria -modificado por la Disposición final octava de la LRJSP- el sector público estatal está compuesto por el sector público administrativo, el empresarial y el fundacional. 
aplican al sector público a partir de lo dispuesto en su artículo 2. Volveremos, no obstante, sobre este particular en la parte final de este trabajo.

Recuperando ahora el epicentro del nuevo escenario de aplicación de la legislación de contratos, es la Exposición de Motivos de la LCSP07 la que en su momento dejó claras muestras del ambicioso propósito que asumía y que para nada era neutro. La LCSP07, por la que se transponía al ordenamiento jurídico interno la Directiva 2004/18, de 31 de marzo, provoca, más que una implosión, una verdadera explosión en el contorno del concepto de Administración pública y del derecho administrativo. Un derecho administrativo que ya no pasa a ser identificado únicamente como el derecho de las Administraciones públicas, sino que, por extensión, como el derecho administrativo "del sector público" ${ }^{115}$. De esta forma, queda materializada no solo para la legislación de contratos, sino para el conjunto de la legislación administrativa, la que podemos identificar como "afectación administrativa de lo público". Afección que no será la única como quiera que, diez años más tarde, la LCSP17, lejos de consolidar el fundamento material de la Administración pública por "sentimiento de pertenencia" a la familia del sector público, provoca ahora también una "afectación administrativa" pero de "lo privado". Una vez más, la identidad funcional del sujeto del que se predica un comportamiento, en este caso una eventual contratación, desencadena una irradiación administrativa sin ambages en la aplicación de la legislación de contratación pública.

La constatación del germen de esta irrupción en la caracterización jurídica de los sujetos que integran el llamado sector público es tenida en cuenta por el Consejo de Estado en su Dictamen 514/2006, de 25 de mayo, al Anteproyecto de Ley de contratos del sector público. De este modo, se destaca como uno de los aspectos reveladores del nuevo enfoque normativo la ampliación del ámbito subjetivo de aplicación, "no ya mediante la extensión parcial de las previsiones legales pensadas para el contrato de la Administración pública stricto sensu a ciertos sujetos y contratos incluidos en el ámbito de aplicación del derecho comunitario, sino construyendo desde el inicio la ley de contratación pública como una ley del sector público en el sentido más amplio posible" ${ }^{1186}$.

85 Jorge García-Andrade, "El 'Sector Público' como referente actual del derecho administrativo", Revista de Administración Pública, n. ${ }^{\circ}$ 209, 2019 p. 179, ha recreado recientemente este fenómeno de expansión del derecho administrativo y consecuente redefinición de su ámbito de aplicación, "ampliándolo sensiblemente hasta conformar la actual categoría del sector público". Una expansión del ámbito subjetivo de aplicación que, a juicio de este mismo autor, "es particularmente elocuente en materia contractual".

86 Página 14 del Dictamen 514/2006, de 25 de mayo, al Anteproyecto de Ley de contratos del sector público. 
En efecto, con la aprobación de la LCSP07 no se esconde la intención, en su propia Exposición de Motivos, de "desarrollar la ley de contratos como una norma que, desde su planteamiento inicial, se diseñe teniendo en cuenta su aplicabilidad a todos los sujetos del sector público". Esto mismo

permite dar una respuesta más adecuada a los problemas antes apuntados aproximando su ámbito de aplicación al de las normas comunitarias de referencia, incrementando la seguridad jurídica al eliminar remisiones imprecisas y clarificar las normas de aplicación [...] y previendo un nicho normativo para que, en línea con las posiciones que postulan una mayor disciplina en la actuación del sector público en su conjunto, puedan incluirse reglas para sujetos que tradicionalmente se han situado extramuros de esta legislación.

El sector público representa, así pues, en materia de contratación pública, la figura paternal que propicia el regreso esperado del ente público "pródigo" que ha de tornar al sistema del que nunca debió salir y marcar así el destino de los intentos de huida que todavía algún ente díscolo de la "familia administrativa" quisiera llevar a cabo.

A resultas de lo anterior, lo verdaderamente relevante para el nuevo régimen europeo de contratos es que la contratación en cuestión tenga lugar en el seno del sector público de modo que la actuación del sector público -criterio material funcional- entre dentro del ámbito de aplicación de la normativa de contratos públicos con independencia de la veste organizativa o el "ropaje" -criterio subjetivo u orgánico- que porte el sujeto que contrata o tiene intención de contratar. Como quiera que toda la atención se centra a partir de entonces en la acción o funcionalidad del sujeto más que en el sujeto mismo ${ }^{87}$, la contratación pública, como en su momento lo fue la libre circulación de los trabajadores en la función pública ${ }^{88}$, supone un buen acicate conforme al cual los Estados miembros están llamados a experimentar una pérdida de su

87 Téngase en cuenta que una circunstancia similar a la que nos referimos ahora con la noción de Administración pública en materia de contratación pública ya aconteció con las llamadas empresas públicas en el ámbito del derecho europeo de la competencia en los términos destacados en su día por SANTiago MuÑoz MACHADO, La Unión Europea ..., óp. cit., p. 135. De esta manera, hoy día, como consecuencia de la acción de la jurisprudencia europea, el concepto vigente de empresa pública lo es apoyado en criterios puramente económicos o funcionales, antes que, en concepciones de carácter orgánico, como también acontece de igual modo con los sujetos que se desenvuelven en el campo de la contratación pública.

88 Como el TJCE reconoció, ya tempranamente, en la sentencia de 21 de junio de 1974 (asunto 2/74), "no puede admitirse que los principios que contiene el Tratado resulten limitados por una interpretación de lo que sea la Administración pública, tomada solo del derecho de cada uno de los Estados miembros, pues esto llevaría a la inaplicación del derecho comunitario". Véase más ampliamente el trabajo de Mariano Baena del AlCázar y Marcel Piquemal, "Las Administraciones nacionales ante la Unión Europea", Revista Española de Derecho administrativo, n. ${ }^{\circ}$ 90, 1996. 
capacidad de identificar lo que sea y lo que quepa entender por Administración pública $^{89}$. Un término sometido a una cada vez más creciente europeización en pos de la máxima aplicación del ordenamiento jurídico europeo ${ }^{90}$ y que, fruto de esa incesante expansión, se ve superado "por arriba" por la realidad del sector público.

Una de las novedades, por no decir la más importante, que ha introducido la regulación de la normativa de contratos del sector público respecto de la legislación inmediatamente anterior viene constituida por la nueva delimitación extensiva que se formula de su ámbito de aplicación. En este sentido, y para guardar la debida coherencia con el nuevo régimen europeo (en un primer estadio la Directiva 2004/18 y de forma más reciente las directivas 2014/23 y 2014/24), la delimitación de los sujetos afectados por el régimen de contratación pública se realiza en términos muy amplios, prácticamente sin parangón hasta entonces en relación con la legislación precedente. La normativa europea ejerce una nueva "presión" haciéndose eco del sentir previamente manifestado por el TJCE, entre otras en la sentencia de 4 de julio de $2006^{[91]}$, donde expresamente se alude al Estado y al "sector público en sentido amplio". Asistimos pues al empuje más fuerte y conocido hasta el momento que incide de lleno en la noción de Administración pública y con ella en la de derecho administrativo, como podremos comprobar acto seguido.

A diferencia de la fórmula -en exceso recurrente de nuestro legislador-por la que se afirma que "se entiende por Administraciones públicas a los efectos de esta ley" y con las propias limitaciones que ello supone, el artículo 3.1 LCSP07 (y luego el Texto Refundido de la LCSP de 2011) apostaron por "dinamitar" ese corsé normativo anterior disponiendo que "a los efectos de esta ley, se considera que forman parte del sector público los siguientes entes, organismos y entidades".

No deja de resultar revelador cómo la LCSP07 ya no se atreve a decir en un primer momento 92 "se entienden por Administraciones públicas", quizás plenamente consciente de su limitada capacidad y de los problemas que ello

89 Hasta el punto que, cada vez de forma más palpable, resulta irrelevante, en palabras de Mario P. CHITI, "El organismo de derecho público...", óp. cit., p. 45, la calificación formal que un sujeto posea según el derecho nacional con el objeto de su posible calificación como organismo de derecho público y su consecuente inclusión en el ámbito de aplicación de la normativa europea de contratos.

90 A partir de la consolidada jurisprudencia del TJuE, el objetivo último no es otro que las directivas en materia de contratación pública se cumplan, y ello "con independencia de cómo actúe la concreta organización de cada Estado miembro". Véase MarTín María RAZquín LizárRaGa, "La jurisprudencia del Tribunal de Justicia...", óp. cit., p. 16.

91 Sentencia del TJCE de 4 de julio de 2006, asunto C-212/04.

92 Bien es cierto, todo sea dicho, que el artículo 3.2 luego se refiere a que "dentro del sector público, y a los efectos de esta ley, tendrán la consideración de Administraciones públicas los siguientes entes, organismos y entidades". 
entrañaba ${ }^{93}$. Por encima del sujeto, ente u organismo que contrata -epicentro de la primera normativa en materia de contratación pública-, lo verdaderamente relevante, como rezuma del propio artículo 1 LCSP07, es la actividad contractual desarrollada en el seno del sector público. El referente funcional es el medio normativo empleado para identificar a los sujetos a los que se les va a aplicar posteriormente la Ley de contratos. Una interpretación funcional y amplia del concepto de organismo de derecho público, en línea con la jurisprudencia del TJCE ${ }^{94}$, que implica la inclusión en el mismo de las sociedades mercantiles bajo control público ${ }^{95}$, siempre que cumplan los requisitos establecidos en el artículo 1.b párrafo segundo de la Directiva 93/37. Para ello, y con la finalidad de ajustar el ámbito de aplicación de la Ley al de las Directivas europeas,

93 No podemos obviar la condena al Reino de España declarada por la sentencia del TJCE de 13 de enero de 2005 (asunto C-84/03) por incumplir las obligaciones que le incumben en relación con la Directiva 93/36, de 14 de junio, sobre coordinación de los procedimientos de adjudicación de contratos públicos de suministro, y la Directiva 93/37, de 14 de junio, sobre coordinación de los procedimientos de adjudicación de los contratos públicos de obras. Esta condena se produjo al no haber adaptado España correctamente al ordenamiento jurídico interno las citadas directivas, en particular por: a) excluir del ámbito de aplicación del TRLCAP -artículo 1.3- las entidades de derecho privado que reúnan los requisitos recogidos en el artículo 1.2.b, apartados primero, segundo y tercero de ambas directivas; y b) excluir absolutamente del ámbito de aplicación del TRLCAP -artículo 3.1.c- los convenios de colaboración que celebren las Administraciones públicas con las demás entidades públicas $y$, por ende, también los convenios que constituyan contratos públicos a efectos de dichas directivas. Sobre este último particular resulta de especial interés la reciente sentencia del TJuE de 4 de junio de 2020 (asunto C-429/19), relativa a los contratos celebrados entre entidades del sector público en el marco de una cooperación entre los mismos y donde se analiza la delimitación de figuras para determinar cuándo un convenio de cooperación cumple las exigencias para ser un negocio excluido del artículo 12 de la Directiva 2014/24 (artículo 6 LCSP 17).

94 Véase claramente por lo que respecta a nuestro país las sentencias del TJCE de 15 de mayo de 2003 (asunto C-214/00 Comisión c. España) y de 13 de enero de 2005 (asunto C-84/03 Comisión c. España).

95 Nótese que mientras la Disposición adicional sexta de la LCAP de 1995 (del TRLCAP de 2000) disponía que "las sociedades mercantiles en cuyo capital sea mayoritaria la participación directa o indirecta de las Administraciones públicas o de sus organismos autónomos, o entidades de derecho público, se ajustarán en su actividad contractual a los principios de publicidad y concurrencia, salvo que la naturaleza de la operación a realizar sea incompatible con estos principios", el artículo 3.1.d LCSP07 (y del Texto Refundido de la LCSP de 2011) considera que "forman parte del sector público" -y por tanto quedan sujetos a la ley los contratos que celebren, cualquiera que sea su naturaleza jurídica- "las sociedades mercantiles en cuyo capital social la participación, directa o indirecta, de entidades de las mencionadas en las letras a) a f) del presente apartado sea superior al 50\%". Véase sobre este concreto particular la interesante sentencia del TJCE de 16 de octubre de 2003 (asunto C-283/00 Comisión c. España) en el conflicto en que las autoridades españolas discutían que la Directiva 93/37, al igual que las Directivas 93/36 y 92/50, no incluía en el concepto de organismo de derecho público a las sociedades mercantiles bajo control público, extremo este no aceptado por la Comisión ni por el TJCE. 
así como para no dejar entidades del sector público exentas de regulación, la delimitación de los entes sujetos se realizaba en términos necesariamente muy amplios. De esta forma, en el artículo 3.1 LCSP07 pasaban a enunciarse -letras a-g-las entidades y organismos que se consideraba conveniente que en todo caso quedasen sujetos a la legislación de contratos del sector público. Esto con el referente de la concepción del "sector público" arrastrada por la Ley General Presupuestaria, si bien con las pertinentes correcciones terminológicas para permitir la extrapolación de sus categorías a los sectores autonómico y local, e incorporar menciones expresas a las universidades públicas y a las autoridades reguladoras independientes. Y como garantía del entero sistema, la letra h del artículo 3.1 LCSP07 operaba como "cláusula de cierre", acomodándose de esta forma a los postulados europeos marcados por la doctrina del TJCE a la hora de interpretar las directivas de los años noventa -fundamentalmente por lo que se refiere al criterio de la satisfacción de necesidades de interés general-, tal y como hemos comprobado ut supra. De este modo, y prácticamente reproduciendo el concepto europeo de organismo de derecho público, también quedaban incluidos

cualesquiera otros entes, organismos o entidades con personalidad jurídica propia, que hayan sido creados específicamente para satisfacer necesidades de interés general que no tengan carácter industrial o mercantil, siempre que un sujeto perteneciente al sector público financie mayoritariamente su actividad, controle su gestión o nombre a más de la mitad de los miembros de su órgano de administración, dirección o vigilancia.

Con todo, y a resultas de esta inclusión genérica y finalista ${ }^{96}$, la LCSP07 (y también el posterior Texto Refundido de la LCSP de 2011) se hacía eco -y asumía como no podía ser de otro modo- la definición de "organismo público" -en cuanto poder adjudicador- recogida en la Directiva 2004/18 (artículo 1 apartado 9) que a su vez traía causa de la jurisprudencia interpretativa del TJuE y que incluye tanto entidades públicas como privadas siempre que se dirijan a satisfacer necesidades de interés general no industriales ni mercantiles. De la aplicación "residual" de la LCAP de 1995 (artículo 2.1) con la LCSP07, las entidades de derecho público que operan bajo el régimen de derecho privado pasan a quedar dentro de la aplicación de la normativa en materia de contratación pública (artículo 3.1 apartados c y h) pero con una diferencia sustancial con efectos para la conformación, cada vez más amplia del derecho administrativo

96 Como recuerda el Consejo de Estado en su Dictamen 1116/2015, de 10 de marzo de 2016 al anteproyecto de Ley de contratos del sector público, esta categoría, un tanto abstrusa y de difícil interpretación, fue introducida en la LCSP07 a modo de cortafuegos para salvar las continuas condenas que España estaba recibiendo del TJCE al dejar fuera del ámbito de aplicación de la legislación de contratos a diversas entidades públicas (p. 56). 
(y por ende del derecho de las Administraciones públicas). Porque mientras en la primera legislación administrativa de contratos (LCAP de 1995 y TRLCAP de 2000) se consideraban como Administraciones públicas (a los efectos de la ley) únicamente a las tres Administraciones territoriales (estatal, autonómica y local), en el siguiente estadio normativo en materia de contratación pública (LCSP07 y TRLCSP de 2011) se ensancha el perímetro de los sujetos que, dentro del sector público, tienen, además, la consideración de Administraciones públicas. En este sentido, junto a las Administraciones territoriales, también pasan a gozar de tal condición los organismos autónomos, universidades públicas, autoridades administrativas independientes y las entidades de derecho público que operan bajo el derecho público (a excepción de las entidades de derecho público que se rigen por el derecho privado, como lo son de manera paradigmática las entidades públicas empresariales ${ }^{97}$ ).

En definitiva, la inclusión del concepto europeo de organismo público nos sitúa, como ya dejara constatado Chiti ${ }^{98}$, ante un concepto "abierto", y sin duda ante la parte más original del concepto europeo de Administración pública, para descender así, en vía interpretativa, "a lo específico de las diversas normativas nacionales". Porque el objetivo último que se persigue con ello, como subyace en la jurisprudencia del TJCE, no es otra cosa que garantizar plenamente que el ámbito de aplicación de la ley se extienda a cualquier organismo o entidad que, con arreglo a la Directiva 2004/18, deba estar sometido a sus prescripciones, a saber: a) entes, organismos, o entidades con personalidad jurídica propia ${ }^{99}{ }_{i}$ b) creados específicamente para satisfacer necesidades de interés general que no tengan carácter industrial o mercantil ${ }_{i}$ c) siempre que un sujeto perteneciente al sector público financie mayoritariamente su actividad, controle su gestión o nombre a más de la mitad de los miembros de su órgano de administración, dirección o vigilancia.

Llegados a este punto, en el último apartado de este trabajo, interesa concretar qué es lo que ha supuesto, por consolidación, la aprobación del último paquete de Directivas de 2014 en materia de contratación pública y de la actualmente vigente LCSP17 en la noción de Administración pública y en la amplia recreación del concepto de sector público.

97 Que, aunque bajo los postulados de la LCSP07 no tienen la consideración de Administración pública, sí forman parte del sector público a los efectos de la aplicación de la normativa de contratación pública.

98 Mario P. Chiti, "El organismo de derecho público...", óp. cit., p. 38.

99 Téngase en cuenta que la interpretación del requisito de la personalidad jurídica es independiente de la forma jurídica, pública o privada, de la entidad en cuestión 


\section{LA "ELASTICIDAD" DEL CRITERIO FUNCIONAL Y LA VIS EXPANSIVA DEL SECTOR PÚBLICO: LA AFECTACIÓN ADMINISTRATIVA DE LO PRIVADO}

La regulación tradicional en materia de contratación pública ha girado en torno al contrato de la Administración pública, esto es, el celebrado por la misma. A partir de la fuerza normativa de las directivas europeas y de la labor interpretativa, fuertemente condicionante, del TJCE ${ }^{100}$, se abre, por pura necesidad de garantizar la libre competencia, la posibilidad de extender también la aplicación de las normas públicas de contratación a los contratos celebrados por otros sujetos del sector público e, incluso, de afuera de él. La aprobación de las directivas de la cuarta generación en materia de contratación pública ha mantenido, sin modificaciones, el ámbito de aplicación ratione personae de la Directiva 2004/18 y, por ende, la definición funcional de poder adjudicador en la que se basaba el TJCE, si bien incorporando determinadas aclaraciones. Unas matizaciones que no solo vienen a consolidar el concepto funcional de organismo de derecho público ${ }^{101}$ como poder adjudicador sino, incluso, a proyectar una afección administrativa a sujetos que no solo no tienen la consideración de Administración pública, sino que tampoco orbitan, ordinariamente, alrededor de la galaxia conformada por el sector público.

La explicación a este fenómeno, que colisiona con la sistematicidad estatutaria tradicional del derecho administrativo, se encuentra en el fin perseguido por el corpus iuris que conforman las directivas de 2014: la transparencia del mercado y la erradicación a toda costa de cualquier atisbo de corrupción. Con ello se trasciende la garantía de la eficacia de la gestión administrativa -que pasa a un segundo plano- para primar, ante todo, la del mercado. Y en el plano estrictamente organizativo, que es el que aquí y ahora más nos interesa, la consecución de ese objetivo se cimenta por las directivas de 2014 redoblando esfuerzos en torno al concepto funcional de poder adjudicador ${ }^{102}$. Hasta el punto de erigirlo completamente ajeno a las formas de personificación pública del sector público y, por consiguiente, de los sujetos ordinariamente sometidos a su regulación, como es ahora el caso peculiar de los partidos políticos.

100 Véase Dimitry Berberoff Ayuda, "La doctrina del Tribunal de Justicia de la Unión Europea en la contratación pública como condicionante interpretativo", en José María Gimeno Feliú (ed.), Estudio sistemático de la Ley de contratos del sector público, Cizur Menor: Thonsom Aranzadi, 2018, pp. 163-202.

101 Y del que se siguen predicando las tres características acumulativas que ya nos constan, a saber: a) satisfacción de necesidades de interés general que no tengan carácter industrial

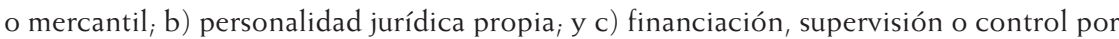
parte de Administraciones territoriales u otros organismos de derecho público. Cfr. artículo 6.4 de la Directiva 2014/23 y artículo 2.4 de la Directiva 2014/24, de 26 de febrero.

102 Véase artículo 6.1 de la Directiva 2014/23 y artículo 2.1 de la Directiva 2014/24, de 26 de febrero. 
La propia Directiva 2014/24, de 26 de febrero, sobre contratación pública y por la que se deroga la Directiva 2004/18 lo evidencia muy claramente en su considerando $29^{[103]}$. En este sentido, la Directiva 2014/24 únicamente se aplica a los poderes adjudicadores de cada uno de los Estados miembros, concepto en el que no cabe incluir, en un principio, a los partidos políticos en general. Empero, y esto es lo verdaderamente relevante, "puede darse el caso, en algunos Estados miembros, de partidos políticos que se incluyan en el concepto de organismos de derecho público".

La traslación de esa nueva extensión del concepto funcional de poder adjudicador no se ha hecho esperar, como no podía ser de otro modo, en la LCSP 17. La vigente legislación española en materia de contratación pública mantiene la existencia de tres niveles de aplicación de la ley, en función de la concreta naturaleza del ente contratante, respecto de las entidades del sector público que conforman su ámbito de aplicación. El sistema se construye a partir de un esquema de círculos concéntricos donde dentro del sector público existe un subgrupo de entidades con la condición de poderes adjudicadores, dentro del cual se inserta, a su vez, la noción de Administración pública. De esta forma, el artículo 3.1 LCSP17 enuncia un listado de sujetos que se considera forman parte del sector público y que, salvo algunos matices, mantiene una, por otra parte, lógica correspondencia con los sujetos que forman parte del sector público bajo la égida de la LRJSP ${ }^{104}$. Aunque cabe añadir que la correspondencia no es exactamente completa entre uno y otro texto legal a los efectos, sobre todo, de los sujetos del sector público que tienen además la consideración de Administración pública. Porque la LRJSP reduce restrictivamente, frente al llamado sector público institucional, la condición de Administración pública (artículo 2.3) a las Administraciones territoriales y a "los organismos públicos y entidades de derecho público previstos en la letra a del apartado 2", esto es, "cualesquiera organismos públicos y entidades de derecho público vinculados o dependientes de las Administraciones públicas [territoriales]", lo que quiere decir, organismos autónomos y entidades públicas empresariales. Mientras que la LCSP 17 amplía ese carácter de Administración pública reconociendo esa naturaleza (artículo 3.2) a sujetos que bajo el rigor de la LRJSP no la tienen stricto sensu, como es el caso significativo de las universidades públicas.

Pero quizás la situación más "fronteriza" la ocupan las entidades públicas empresariales. Tanto en una como en otra disposición normativa, en la

103 Véase también, en el mismo sentido, el considerando 37 de la Directiva 2014/23, de 26 de febrero, relativa a la adjudicación de contratos de concesión.

104 De hecho, la Exposición de Motivos (apartado v) de la LCSP17 reconoce expresamente que "se ha adaptado la tipología de las entidades incluidas dentro del ámbito subjetivo a la establecida en la nueva Ley de Régimen Jurídico del Sector Público, Ley 40/2015, de 1. ${ }^{\circ}$ de octubre". 
actualidad, las Entidades públicas empresariales, como organismos públicos que son ${ }^{105}$, integran el sector público si bien, todo sea dicho, resulta paradigmática la mención separada que, en la actualidad, hace el legislador estatal de las entidades públicas empresariales. Porque se mencionan en el apartado g del artículo 3.1 LCSP 17 en lugar de aparecer enunciadas en el apartado c del mismo precepto junto con los organismos autónomos (y las universidades públicas y las autoridades administrativas independientes), tal y como por contra sí hacía la LCPS07 (artículo 3.1.c) una década antes. Sea como fuere, las Entidades públicas empresariales, en tanto que organismos públicos con la consideración de Administración pública conforme a la LRJSP (artículo 2.3 en relación con el artículo 2.2.a), carecen de esa naturaleza de Administración pública a los efectos de la normativa de contratación pública. La actual LCSP17 no las menciona en el artículo 3.2. Ni en su apartado a, entre el elenco de entidades a las que expresamente se les otorga ese carácter. Ni tampoco cabe deducir tal posibilidad de su apartado $b$, porque no reúnen las condiciones dispuestas para las entidades de derecho público ahí recogidas. En efecto, el artículo 107.3 LRJSP dispone que las Entidades públicas empresariales "se financiarán mayoritariamente con ingresos de mercado. Se entiende que se financian mayoritariamente con ingresos de mercado cuando tengan la consideración de productor de mercado de conformidad con el Sistema Europeo de Cuentas". Prescripción que es justo la que en sentido inverso determina el artículo 3.2.b LCSP17 para el reconocimiento, como Administraciones públicas, de "otras entidades de derecho público, en las que dándose además las circunstancias establecidas en la letra d) del apartado siguiente para poder ser considerados poder adjudicador y estando vinculados a una o varias Administraciones públicas dependientes de las mismas".

Esta decisión del legislador se mantiene invariable desde la anterior LCSP07, donde de manera expresa el último párrafo de su artículo 3.2 niega la consideración de Administración pública a las entidades públicas empresariales ${ }^{106}$ ante

105 Véase artículo 84.1.a LRJSP.

106 También podía deducirse, a sensu contrario, del apartado e del artículo 3.2 LCSP07 donde se atribuía el carácter de Administración pública a las entidades de derecho público vinculadas o dependientes de cualquiera de las Administraciones territoriales que cumplieran alguna de las siguientes condiciones: a) que su actividad principal no consista en la producción en régimen de mercado de bienes y servicios destinados al consumo individual o colectivo, $\mathrm{y}$ b) que no se financien mayoritariamente con ingresos, cualquiera que sea su naturaleza, obtenidos como contrapartida a la entrega de bienes o a la prestación de servicios. Ambas características dificultan el reconocimiento de las Entidades públicas empresariales como Administración pública dado su régimen y naturaleza eminentemente prestacional (desarrollan actividades prestacionales, de gestión de servicios o de producción de bienes de interés público, susceptibles de contraprestación y se financian mayoritariamente con ingresos de mercado). Véase artículo 103.1 LRJSP y, precedentemente, al tiempo de la vigencia de la LCSP07, artículo 53.1 de la derogada Ley 6/97, de 14 de abril, de organización y funcionamiento de la Administración general del Estado. 
su actividad prestacional de mercado y su competencia con sujetos privados de forma que el reconocimiento de la condición de Administración pública a los solos efectos de contratación podría llegar a comprometer la libre competencia en el acceso a recursos en condiciones de igualdad ${ }^{107}$. Porque no es casualidad que las entidades públicas empresariales sean identificadas, junto con las sociedades mercantiles, como parte integrante del llamado sector público empresarial ${ }^{108}$. Lo que no obsta, en todo caso, para que, pese a no ser consideradas ni poder adjudicador ni Administración pública, en tanto que entidades integrantes del sector público, queden sujetas al primer "anillo" concéntrico de sujeción a la normativa de contratación pública, tal y como confirma su régimen jurídico al amparo de lo dispuesto en la legislación administrativa general ${ }^{109}$

Así las cosas, la diferencia de la actual LCSP17 con la LCSP07 es el añadido de más sujetos dentro del paraguas del sector público a los efectos de la contratación pública, como es el caso de los fondos sin personalidad jurídica ${ }^{110}$

107 Conforme advirtió en su momento Andrés Betancor RodríGueZ, "Las entidades públicas empresariales en la Ley de Organización y Funcionamiento de la Administración General del Estado o la inconstitucionalidad de que la Administración sea al mismo tiempo Administración y empresa", Documentación Administrativa, n. ${ }^{\circ}$ 246-247, 1997, pp. 439-493, nos encontramos ante entes públicos que realizan actividad empresarial sometidos al derecho privado. Pero también pueden ejercer potestades administrativas $y$, en ese caso, quedar sometidos al derecho administrativo. Resulta con ello una "suerte" de Administraciónempresa. Una mixtura no exenta de problemas. Porque aquí no se trata de que un ente público este sujeto al derecho privado, así sin más, sino del hecho que una empresa, desde el punto de vista material y europeo a los efectos de la contratación pública, revista el ropaje formal de un ente público para competir en el mercado. Estas mixturas no solo son contrarias al derecho europeo sino también a la Constitución por la distorsión que crean en el seno del mercado. Véase sobre este último particular Santiago Muñoz Machado, "La noción de empresa pública, la libre competencia y los límites del principio de neutralidad", en Alfonso Pérez Moreno (coord.), Administración instrumental. Libro bomenaje a Manuel Francisco Clavero Arévalo, vol. II, Madrid: Civitas, 1994.

108 Véase artículo 3.2 de la Ley 47/2003, de 26 de noviembre, General Presupuestaria y artículo 166.1 de la Ley 33/2003, de 3 de noviembre, del Patrimonio de las Administraciones Públicas.

109 Así, "la contratación de las entidades públicas empresariales se rige por las previsiones contenidas al respecto en la legislación de contratos del sector público" (artículo 106.6 LRJSP). Ahora bien, que el artículo 91.2.b LRJSP disponga que las leyes de creación de los organismos públicos pueden establecer "las peculiaridades de su régimen de personal, de contratación, patrimonial, fiscal y cualesquiera otras que, por su naturaleza, exijan norma con rango de ley" otorga carta de naturaleza para que el propio legislador estatal se aparte con cierta (si no entera) libertad del régimen general que, de otro modo, resultara aplicable.

110 La inclusión de los fondos sin personalidad jurídica -identificados como sector público institucional estatal en el artículo 84.1.f LRJSP- en la LCSP 17 constituye una buena muestra de la concepción subjetiva dispuesta por las directivas europeas en materia de contratación pública. De este modo, los sujetos a los que les resultan de aplicación sus previsiones son identificados desde un punto de vista funcional y no meramente orgánico (en el caso de 
(apartado i) así como con las entidades que, dentro del sector público, tienen la consideración de Administraciones públicas (apartado 2) donde prácticamente se reproducen los mismos sujetos que ya aparecen reconocidos con ese carácter en la LCSP07. Pero, sin lugar a dudas, la principal novedad de la LCSP 17 viene dada por los apartados 4 y 5 de su artículo 3 donde "se ha extendido el ámbito subjetivo, con la idea de aplicar estas normas a entidades no sujetas", tal y como reconoce la propia Exposición de Motivos (apartado v), de cara a fomentar la transparencia en la contratación pública. Apreciamos, de este modo, una "elasticidad", sin precedentes, del criterio funcional de poder adjudicador provocando la que hemos dado en denominar ut supra afección administrativa de lo privado ${ }^{111}$.

De hecho, el apartado 4 del artículo 3 LCSP17 se refiere a los partidos políticos, los sindicatos, las organizaciones empresariales y las asociaciones profesionales (además de las fundaciones y asociaciones vinculadas a cualquiera de ellos). Ninguno de estos sujetos, no solo no se identifican con la noción típica de Administración pública, sino que no forman parte tampoco del concepto más amplio de sector público. Sin embargo, la legislación actualmente vigente en materia de contratación pública alude a ellos, no tanto como personificaciones públicas sino más bien como sujetos (privados) "de interés público". De ahí que la LCSP17 incluya un nuevo "cinturón de seguridad", un escalón más en el ámbito subjetivo de aplicación de la Ley ${ }^{112}$. A todos estos sujetos-donde lo público y lo privado a veces dibuja perfiles no siempre fáciles de discernir, como es el caso de un partido político o un sindicato que encarnan también realidades de interés público- el apartado 4 del artículo 3 LCPS 17 les impone, respecto de los contratos sujetos a regulación armonizada, el cumplimiento ${ }^{113}$ de "los principios de publicidad, concurrencia, transparencia, igualdad y no discriminación sin perjuicio del respeto a la autonomía de la voluntad y de la confidencialidad cuando sea procedente". La aplicación de estos principios de contratación pública a sujetos que no forman parte del sector público se

los fondos como sujetos del tráfico económico pese a su evidente falta de personalidad jurídica).

111 Téngase en cuenta, no obstante, que ya en la LCSP07 resultaba posible reconocer el carácter de poder adjudicador a sujetos privados, como era el caso de los concesionarios de obra pública conforme al artículo 250.1.

112 Realmente, como ha reconocido con propiedad el Consejo de Estado en su Dictamen 1116/2015, de 10 de marzo de 2016 al anteproyecto de Ley de contratos del sector público, más bien "se trata de una extensión de la regulación legal y no una inserción de dichas entidades en el concepto de sector público" (p. 57).

113 En una situación muy parecida a la que se perfilaba en la LCAP de 1995 para las sociedades mercantiles. Recuérdese en este sentido la disposición adicional sexta de la citada ley relativa a los principios de contratación en el sector público aplicables a unas sociedades mercantiles que no aparecían enunciadas en el ámbito subjetivo de aplicación, como acontece ahora en la LCSP17 con los partidos políticos, sindicatos y organizaciones empresariales y profesionales. 
produce en la medida, además, que "cumplan los requisitos para ser poder adjudicador de acuerdo con la letra d) del apartado 3 del presente artículo". Esta coletilla del apartado 4 supone un pórtico de entrada al concepto funcional de organismo de derecho público y su aplicación extensiva y "elástica" ahora también a todos estos otros sujetos (no públicos) en su eventual reconocimiento como poderes o entidades adjudicadores no Administración pública ${ }^{144}$. Porque, recuérdese, los requisitos de la letra $\mathrm{d}$ del apartado 3 vienen asociados a otras entidades de derecho público

que hayan sido creadas específicamente para satisfacer necesidades de interés general que no tengan carácter industrial o mercantil, siempre que uno o varios sujetos que deban considerarse poder adjudicador de acuerdo con los criterios de este apartado 3, bien financien mayoritariamente su actividad; bien controlen su gestión; o bien nombren a más de la mitad de los miembros de su órgano de administración, dirección o vigilancia.

Misma condición a cumplir e iguales requisitos que, en la medida en que se prediquen de las corporaciones de derecho público ${ }^{115}$, determina igualmente su sujeción a los dictados de la Ley de contratos conforme prescribe su artículo 3 apartado 5 .

En suma, el reconocimiento de los "fundamentos materiales" del concepto de Administración pública, por mor de los postulados de las directivas y de la jurisprudencia europea en materia de contratación pública, se encuentran en un proceso constante de aproximación y unificación ${ }^{116}$. Una aproximación y unificación que se ciernen inexorablemente sobre la autonomía organizativa de los Estados miembros hasta el punto que, como evidencia la normativa en materia de contratación pública, "las nuevas delimitaciones del ámbito subjetivo

114 Véase más ampliamente SILVIA DíEZ SASTRE, "El ámbito subjetivo de la LCSP. La contratación de los poderes adjudicadores no Administración pública", en Eduardo Gamero Casado e Isabel Gallego Córcoles (coords.), Tratado de contratos del sector público, vol. 1, t. I, Valencia: Tirant lo Blanch, 2018, pp. 519-554.

115 Aunque con la significativa diferencia respecto de un partido político, sindicato u organización profesional y/o empresarial que las corporaciones de derecho público no son únicamente sujetos de interés público, sino que nos encontramos ante verdaderas personificaciones jurídico-públicas. Así, ya tempranamente el Tribunal Constitucional, en su sentencia 76/83, de 5 de agosto, señaló que las corporaciones de derecho público tienen dimensión pública y participan de la naturaleza de Administraciones públicas, por lo que, en última instancia, merecen la conceptuación de Administraciones corporativas. Y más recientemente, la Ley 39/2015, de 1 . $^{\circ}$ de octubre, del procedimiento administrativo común de las Administraciones públicas contempla en su artículo 2.4 la aplicación supletoria de la Ley a las Corporaciones de Derecho público en el ejercicio de sus funciones públicas.

116 Eberhard SChmidt-AsSMAnN, La teoría general..., óp. cit., p. 45. 
en la aplicación del derecho comunitario terminan por poner en duda las propias características de la organización pública en los Estados miembros" ${ }^{\prime \prime 17}$.

\section{CONCLUSIONES}

El derecho europeo de la contratación pública ha provocado una reorganización administrativa sin parangón en los derechos internos de los Estados miembros. Una reorganización producida por la progresiva ampliación de los sujetos que pasan a quedar sometidos a las reglas jurídico-públicas en materia de contratos con el fin de aplicarles las garantías de una adjudicación libre y competitiva.

El recorrido por el ámbito subjetivo de la normativa en materia de contratación pública arroja como resultado actual una configuración más funcional del derecho administrativo donde parece importar más "lo que hace" que "lo que es" realmente el sujeto que contrata.

Porque no basta ya con la personificación de las Administraciones públicas como criterio delimitador dado que la finalidad perseguida es someter a todas las organizaciones públicas -cualquiera que sea su forma de personificación o incluso careciendo de ella como es el caso más reciente de los fondos sin personalidad jurídica- a las previsiones de la legislación en materia de contratación pública.

En este mismo sentido, el desarrollo del concepto funcional de poder adjudicador, sustentado en la noción de organismo de derecho público, se ha convertido en auténtico vector de transmisión inoculando el radio subjetivo de acción de la legislación de contratación pública en la legislación administrativa general. Y, en última instancia, transformando la fisonomía del derecho administrativo en la búsqueda de un principio material o sustantivo en la función desarrollada por la Administración pública o de los entes instrumentales vinculados o dependientes de ella.

El estudio abordado en las páginas precedentes evidencia que el derecho administrativo de contratos está compelido a atraer y aglutinar otras realidades que trascienden el concepto "estrecho" de Administración pública y donde resulta obligado considerar tanto la materialidad de la actuación como el propio sujeto administrativo. Asistimos a la recreación de una suerte de "derecho del sector público" que llega a salpicar, además, la actuación de sujetos privados que también presentan un interés público. En definitiva, un derecho administrativo "expandido" que se enfrenta a la tesitura de no mermar su sistematicidad subjetiva (y estatutaria) y ser capaz, al mismo tiempo, de soportar un imparable proceso de diversificación (y de dispersión) organizativa ad infinitum.

117 Mario P. Chitı, "El organismo de derecho público...", óp. cit., p. 34. 


\section{BIBLIOGRAFÍA}

\section{FUENTES DOCTRINALES}

Alonso García, Ricardo. "Treinta años de Ius Publicum Commune europeo en España". Revista de Administración Pública, n. ${ }^{\circ}$ 200, 2016.

Arroyo Jiménez, Luis. "Derecho administrativo y Constitución española". Revista de Administración Pública, n. ${ }^{\circ}$ 209, 2019.

Baena Del Alcázar, Mariano y Piquemal, Marcel. "Las Administraciones nacionales ante la Unión Europea". Revista Española de Derecho administrativo, n. ${ }^{\circ}$ 90, 1996.

BARNES, JAVIER. "Sobre el procedimiento administrativo: evolución y perspectivas". En Javier Barnes (ed.), Innovación y reforma en el derecho administrativo. Sevilla: Derecho Global, 2006.

Berberoff Ayuda, Dimitry. "La doctrina del Tribunal de Justicia de la Unión Europea en la contratación pública como condicionante interpretativo". En José María Gimeno Feliú, Estudio sistemático de la Ley de contratos del sector público. Cizur Menor: Thonsom Aranzadi, 2018.

Betancor Rodríguez, Andrés. "Las entidades públicas empresariales en la Ley de Organización y Funcionamiento de la Administración General del Estado o la inconstitucionalidad de que la Administración sea al mismo tiempo Administración y empresa". Documentación Administrativa, n. ${ }^{\circ}$ 246-247, 1997, pp. 439-493.

Burdeau, François. Histoire du Droit administratif. París: UPF, 1995.

Cassese, Severiano. La globalización jurídica. Madrid: Marcial Pons - InAP, 2006.

Cassese, Severiano. "Diritto amministrativo comunitario e diritti amministrativi nazionali". En Mario P. Chiti y Guido Greco, Trattato di Diritto amministrativo europeo, vol. I, Milán: Giuffrè Editore, 1997.

Cassese, Severiano. "Il Diritto amministrativo comunitario e la sua influenza sulle amministrazioni pubbliche nazionali". En Luciano Vandelli, Carlo Bottari y Donato Donati (dirs.), Diritto Amministrativo Comunitario. Col. Quaderni della Spisa. Rímini: Maggioli Editore, 1994.

Cassese, Severiano. "Il problema della convergenza dei diritti amministrativi: verso un modello amministrativo europeo?". Rivista trimestrale di diritto e procedura civile, n. ${ }^{\circ} 1,1992$.

Chinchilla Marín, Carmen. "El derecho de la Unión Europea como freno a la huida del derecho administrativo". Revista de Administración Pública, n. ${ }^{\circ}$ 200, 2016. 
Chinchilla Marín, Carmen. "La jurisprudencia del tJue sobre contratos públicos (I): ámbito subjetivo y objetivo de aplicación de las directivas". En Miguel Sánchez Morón (dir.), El derecho de los contratos públicos en la UE y sus Estados miembros. Valladolid: Lex Nova, 2011.

Chiti, Mario P. "El organismo de derecho público y el concepto comunitario de Administración pública". Justicia Administrativa, n. ${ }^{\circ}$ 11, 2001.

Chiti, Mario P. "La aproximación del derecho administrativo nacional a los parámetros europeos: la experiencia italiana". Documentación Administrativa, n. o 248-249, 1997.

Chiti, Mario P. y Greco, Guido. Trattato di Diritto amministrativo europeo. Milán: Giuffrè Editore, 1997.

Cozzio, Michele. "La función de la jurisprudencia en el proceso de europeización de las reglas de contratación pública". En José María Gimeno Feliu (dir.), Observatorio de contratos públicos 2012. Cizur Menor: Thomson Civitas, 2013.

Desdentado Daroca, Eva. La crisis de identidad del derecho administrativo: privatización, buida de la regulación pública y Administraciones independientes. Valencia: Tirant lo Blanch, 1999.

Díez SaStre, Silvia. "El ámbito subjetivo de la LCSP. La contratación de los poderes adjudicadores no Administración pública". En Eduardo Gamero Casado y Isabel Gallego Córcoles (coords.), Tratado de contratos del sector público, vol. 1, t. I, Valencia: Tirant lo Blanch, 2018.

García de Enterría, Eduardo. La lengua de los derechos. La formación del derecho público europeo tras la Revolución francesa. Madrid: Alianza Editorial, 1994.

García de Enterría, Eduardo. "El concepto de personalidad jurídica en el derecho público". Revista de Administración Pública, n. ${ }^{\circ}$ 129, 1992.

García Pelayo, Manuel. Las transformaciones del Estado contemporáneo, 2. ${ }^{\text {a }}$ ed. Madrid: Alianza, 1992.

García-Andrade Gómez, Jorge. "El 'Sector Público' como referente actual del derecho administrativo". Revista de Administración Pública, n. ${ }^{\circ}$ 209, 2019.

Garrido Falla, Fernando. "Origen y evolución de las entidades instrumentales de las Administraciones públicas". En Alfonso Pérez Moreno (coord.), Administración instrumental. Libro bomenaje a Manuel Francisco Clavero Arévalo, vol. I. Madrid: Civitas, 1994.

Gimeno Feliu, José María. "La 'codificación' de la contratación pública mediante el derecho pretoriano derivado de la jurisprudencia del TJuE". Revista Española de Derecho Administrativo, n. ${ }^{\circ} 172,2015$. 
Greco, Guido. "Il Diritto comunitario propulsore del Diritto amministrativo europeo". Rivista trimestrale di Diritto Pubblico, n. ${ }^{\circ} 1,1993$.

Leguina Villa, Jesús. "El ámbito de la jurisdicción". En: Jesús Leguina Villa y Miguel Sánchez Morón (dirs), Comentarios a la Ley de la Jurisdicción contencioso-administrativa,

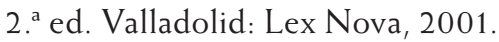

Mackenzie Stuart, Alexander. The European Communities and the Rule of Law. Londres: Stevens and Sons, 1977.

Martín Mateo, Ramón. Manual de derecho administrativo. Cizur Menor: Thomson Aranzadi, 2005.

Martín-Retortillo, Sebastián. "Reflexiones sobre la huida del derecho administrativo". Revista de Administración Pública, n. ${ }^{\circ}$ 140, 1996.

Massera, Alberto. "Una nozione comunitaria di pubblica amministrazione". En Vv. AA., El desenvolupament del Dret administratiu europeu. Barcelona: Escola d'Administració Pública de Catalunya, 1993.

Mir Puigpelat, Oriol. "El concepto de derecho administrativo desde una perspectiva lingüística y constitucional". Revista de Administración Pública, n. ${ }^{\circ} 162,2003$.

Moreno Molina, Ángel Manuel. La ejecución administrativa del derecho comunitario. Régimen europeo y español. Madrid: Marcial Pons, 1998.

MORÍN, ÉDGAR. Introducción al pensamiento complejo. Barcelona: Gedisa, 1992.

Muñoz Machado, Santiago. Tratado de derecho administrativo y de derecho público general,

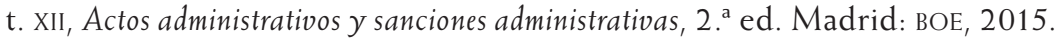

Muñoz Machado, Santiago. Tratado de derecho administrativo y derecho público general, $\mathrm{t}$. I, 2. ${ }^{\text {a }}$ ed. Madrid: Iustel, 2006.

Muñoz Machado, Santiago. "La noción de empresa pública, la libre competencia y los límites del principio de neutralidad". En Alfonso Pérez Moreno (coord.), Administración instrumental. Libro bomenaje a Manuel Francisco Clavero Arévalo, vol. II. Madrid: Civitas, 1994.

Muñoz Machado, Santiago. La Unión Europea y las mutaciones del Estado. Madrid: Alianza Universidad, 1993.

Muñoz Machado, Santiago. "Los principios generales del procedimiento administrativo comunitario y la reforma de la legislación básica española". Revista Española de Derecho Administrativo, n. ${ }^{\circ}$ 75, 1992. 
Muñoz Machado, Santiago. "Las concepciones del derecho administrativo y la idea de participación en la Administración". Revista de Administración Pública, nº 84, septiembre-diciembre 1977.

Nieto, Alejandro. "El derecho comunitario europeo como derecho común vulgar". Revista de Administración Pública, n. ${ }^{\circ}$ 200, 2016.

Parejo Alfonso. Luciano. Derecho administrativo. Barcelona: Ariel, 2003.

Parejo Alfonso, Luciano. Eficacia y Administración. Tres estudios. Madrid: INAP, 1995.

Parejo Alfonso, Luciano. "El ordenamiento español y la integración en las Comunidades Europeas: un problema capital de renovación". Revista Vasca de Administración Pública, n. ${ }^{\circ} 13,1985$.

Pérez Moreno, Alfonso. "La contratación de los entes instrumentales: sociedades mercantiles y demás entidades del sector público". En VV. AA., Comentario a la Ley de contratos de las Administraciones públicas. Madrid: Civitas, 1996.

RazQuín Lizárraga, Martín María. "La jurisprudencia del Tribunal de Justicia de las Comunidades Europeas sobre contratación pública". Justicia Administrativa, n. ${ }^{\circ}$ 6, 2000 .

Rodríguez Iglesias, Gil Carlos. "Consideraciones sobre la formación de un derecho europeo". Gaceta Jurídica de la Unión Europea y de la Competencia, n. ${ }^{\circ}$ 200, 1999.

RufFert, Matthias. "De la europeización del derecho administrativo a la Unión administrativa europea". En Francisco Velasco y Jens-Peter Schneider (coords.), La Unión Administrativa Europea. Madrid: Marcial Pons, 2008.

Santamaría Pastor, Juan Alfonso. "Contratos del sector público y derecho de la Unión". Revista de Administración Pública, n. ${ }^{\circ}$ 200, 2016.

SCHMIDT-AsSmAnN, EBERHARD. La teoría general del derecho administrativo como sistema. Objeto y fundamentos de la construcción sistemática. Madrid: Marcial Pons - INAP, 2003.

SCHMidt-Assmann, Eberhard. "El derecho administrativo general desde una perspectiva europea". Justicia Administrativa, n. ${ }^{\circ}$ 13, 2001.

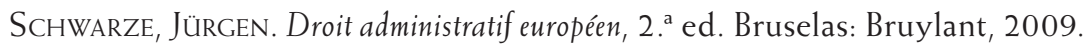

Siegel, Thorsten. Europeización del derecho público. Marco de condiciones y puntos de interacción entre el derecho europeo y el derecho (administrativo) nacional. Madrid: Marcial Pons, 2016.

Von Bogdandy, Armin y Mir Puigpelat, Oriol (coords.). Ius Publicum Europaeum. El derecho administrativo en el espacio jurídico europeo. Valencia: Tirant lo Blanch, 2013. 


\section{FUENTES JURISPRUDENCIALES}

Sentencia del Tribunal de Justicia de las Comunidades Europeas de 12 de febrero de 1974 (asunto 152/73). Sala Cuarta. Petición de decisión prejudicial. Caso Giovani Maria Sotgiu contra Deutsche Bundespost

Sentencia del Tribunal de Justicia de las Comunidades Europeas de 21 de junio de 1974 (asunto 2/74). Sala Cuarta. Petición de decisión prejudicial. Caso Jean Reyners contra Bélgica.

Sentencia del Tribunal de Justicia de las Comunidades Europeas de 17 de diciembre de 1980 (asunto 149/79). Sala Pleno. Recurso de incumplimiento. Caso Comisión de las Comunidades Europeas contra Bélgica.

Sentencia del Tribunal Constitucional 76/83, de 5 de agosto. Sala Pleno. Recurso de inconstitucionalidad. Caso LOAPA.

Sentencia del Tribunal de Justicia de las Comunidades Europeas de 20 de septiembre de 1988 (asunto C-31/87). Sala Cuarta. Cuestión Prejudicial. Caso Gebroeders Beetjes BV contra Países Bajos.

Sentencia del Tribunal de Justicia de las Comunidades Europeas de 30 de mayo de 1989 (asunto C-33/88). Sala Quinta. Cuestión Prejudicial. Caso Pilar Allué y otros contra Università degli studi di Venezia.

Sentencia del Tribunal de Justicia de las Comunidades Europeas de 27 de noviembre de 1991. Sala Tercera. Cuestión Prejudicial. Caso Annegret Bleis contra Ministère de l'Education Nationale.

Sentencia del Tribunal de Justicia de las Comunidades Europeas de 15 de enero de 1998, asunto C-44/96. Sala Pleno. Cuestión Prejudicial. Caso Mannesmann Anlagenbau Austria AG y otros contra Strohal Rotationsdruck GesmbH.

Sentencias del Tribunal de Justicia de las Comunidades Europeas de 2 de julio de 1996. Sala Pleno. Recursos de incumplimiento. Casos Comisión Europea contra Grecia y Comisión Europea contra Luxemburgo.

Sentencia del Tribunal de Justicia de las Comunidades Europeas de 10 de noviembre de 1998 (asunto C-360/96). Sala Pleno. Cuestión Prejudicial. Caso Gemeente Arnhem y otros contra BFI Holding BV.

Sentencia del Tribunal de Justicia de las Comunidades Europeas de $1 .^{\circ}$ de febrero de 2001 (asunto C-237/99). Sala Quinta. Recurso de incumplimiento. Caso Comisión de las Comunidades Europeas contra Francia. 
Sentencia del Tribunal de Justicia de las Comunidades Europeas de 12 de diciembre de 2002 (asunto C-470/99). Sala Sexta. Cuestión Prejudicial. Caso UniversaleBan AG y otros contra Entsorgungsbetriebe Simmering GmbH.

Sentencia del Tribunal de Justicia de las Comunidades Europeas de 15 de mayo de 2003 (asunto C-214/00). Sala Sexta. Recurso de incumplimiento. Caso Comisión de las Comunidades Europeas contra España

Sentencia del Tribunal de Justicia de las Comunidades Europeas de 16 de octubre de 2003 (asunto C-283/00). Sala Sexta. Recurso de incumplimiento. Caso Comisión de las Comunidades Europeas contra España)

Sentencia del Tribunal de Justicia de las Comunidades Europeas de 13 de enero de 2005 (asunto C-84/03). Sala Segunda. Recurso de incumplimiento. Caso Comisión de las Comunidades Europeas contra España.

Sentencia del Tribunal de Justicia de las Comunidades Europeas de 4 de julio de 2006 (asunto C-212/04). Gran Sala. Cuestión Prejudicial. Caso Konstantinos Adeneler y otros contra Ellinikos Organismos Galaktos (ELOG).

Sentencia del Tribunal de Justicia de la Unión Europea de 5 de octubre de 2017 (asunto C-567/15). Sala Cuarta. Petición de decisión prejudicial. Caso LitSpecMet UAB y Vilniaus lokomotyv remonto DEPAS.

Sentencia del Tribunal de Justicia de la Unión Europea de 4 de junio de 2020 (asunto C-429/19). Sala Novena. Cuestión Prejudicial. Caso Remondis GmbH contra M.E. 